\title{
1 Introduction: Demonstratives: Patterns in Diversity
}

Stephen C. Levinson ${ }^{1}$

This book is an in-depth look at demonstratives in 15, nearly all unrelated, languages (see Table 1.1 below). Demonstratives are, of course, the little words (or morphemes) like this and that in English, which serve, in their central function, to pick out a referent in the speech event. ${ }^{2}$ Demonstratives have played a crucial role in linguistic and philosophical thought, but monographic treatments are rare (see Hanks, 1990; Diessel, 1999), and what we know about them crosslinguistically is limited by the paucity of details found in the average grammar of a language. This volume tries to put this right, by examining demonstratives in depth across the 15 languages. A special feature of this collection of studies is that they have used as part of their analysis precisely the same field instrument, thus providing a tertium comparationis, or a grid for precise comparison, of a kind that has never been utilized before. The studies have each been conducted in the field with multiple participants, providing much richer data than is commonly found in language descriptions. This allows us to offer some generalizations about the underlying distinctions found in demonstrative systems with a new certainty. The authors have gone on to supplement this comparison point with observations of their own, derived from long-term investigation in the field. The volume offers a corrective to a large number of preconceptions found in the linguistic, anthropological, psychological and philosophical literature.

This introduction has two major components. A section on preliminaries sketches the state of the art as reflected in the literature from linguistics to brain science. It draws out some of the main issues that make demonstratives so theoretically important, explicates many of the theoretical distinctions that have been made and provides some of the main results from contemporary

1 This introduction has benefitted substantially from elaborate notes on the chapters made by Sarah Cutfield, and from a short draft by Michael Dunn. I am grateful to Gunter Senft, Harald Hammarström, David Peeters, Niclas Burenhult, Penelope Brown and others for comments on earlier drafts.

2 In this introduction the term demonstrative refers in the first instance to the pronominal or adnominal forms, while adverbs like here and there are termed demonstrative adverbs. The demonstrative paradigm of any particular language may include additional elements like anaphoric terms. 
research. The second section of the introduction turns more centrally to the business of this volume, explaining the central task used to structure the studies. A substantial subsection draws together the findings from the separate studies and offers some strong generalizations that have emerged from this collective exercise.

\section{Preliminaries: This Volume in Context}

\subsection{The Importance of Demonstratives}

Demonstratives like this and that are within the top 20 most frequent words in English and are among the most deeply conserved and ancient words in languages (Pagel et al., 2013); indeed, their etymology can rarely be traced (Diessel, 1999, but see Hellwig, this volume; Rosés Labrada, 2015). Demonstratives are also among the earliest words learned by children, and often the first closed-class opposition (Clark, 1978; Tanz, 1980). In acquisition, they follow the earlier use of pointing with which they become associated, pointing marking the initiation of systematic intentional and referential communication, with shared attention focused on a third entity (Tomasello et al., 2005; Liszkowski et al., 2012). The association with pointing makes crystal clear that demonstratives have as one of their most important functions a focusing of joint attention on an object in the environment. This makes them a kind of ideal model system for the study of language use: a single word and gesture can function as a full referring act, with all the complexities of the joint attention, common ground, multimodality and pragmatic integration involved in more complex utterances (Clark et al., 1983). Demonstratives and pointing may also be thought of as an ancient substrate of language, closely allied with animal communication systems which are always concerned with the here and now, showing little of the 'displacement' typical of human language (despite which they figure only rarely in discussions of language origins).

Demonstratives have also played a critical role in our theory of language. They form part of the deictic field, that is, those expressions in a language that are built for contextual resolution, by reference to the situation of speaking. The deictic field is often divided into the semantic domains of space, time, person, discourse and social dimensions, covering not only demonstratives but also temporal expressions like now and tense, personal pronouns like $I$ and you, anaphoric or related expressions, and honorifics (Levinson, 2004). Each of these domains makes essential reference to the context of utterance - one can't resolve Now you do this! without seeing who was addressed when with what demonstration. Deixis poses fundamental problems for understanding the semantics of natural languages and consequently has greatly exercised 
philosophers of language. The tendency has been to conceive of semantics as specifying the states of affairs that match descriptions, with the contribution each linguistic expression makes to that specification being systemically explored. But deictic elements like demonstratives clearly do not play a direct role in that specification - instead, they point to dimensions of the context of utterance which have to be imported to complete the description. A great deal of thought in philosophy and formal semantics has gone into conceptualizing the mechanisms involved, with meaning and reference relativized to context (see, e.g., Braun, 2015 for review), so that You made this can be explicated as, say, 'Anne E. Smith made the indicated painting on or before 7th May 2017'. From the point of view of a cognitive theory of language, this is problematic, because it may not conform to the thought the utterer had in mind when he spoke (perhaps he thought the painting was a photograph and that the maker was called Alice). This dilemma has never been satisfactorily resolved in the theory of semantics (Levinson, 2004). In addition, the paradoxes of selfreference (as in This statement is false) have teased philosophers for two millennia. Deixis is what makes languages special and especially complicated compared to the artificial languages of logic and computation because the incorporation of contextual factors into referential language produces a hybrid system which resists any easy theoretical reduction.

Demonstratives have always been taken to be the prototype elements of deixis (the term comes from the Greek for 'pointing') and have played a key role in semantic theory. It is therefore surprising how relatively little direct exploration of demonstrative semantics and use has been undertaken in any specific language (with exceptions noted below; see also Weissenborn and Klein, 1982; Senft, 1997; 2004; Levinson and Wilkins, 2006). Another gap has been systematic comparison of demonstrative systems across languages, taking into account the details of how the semantics and usage vary across languages. This volume aims to at least partially fill these gaps.

How does one recognize a demonstrative in an unfamiliar language? Largely by function: demonstratives are specialized to refer by exploiting aspects of the context of the speech event to which they direct attention, and hence they often expect a corresponding gesture. It is actually quite difficult to specify the function exactly. Diessel (2006) suggests the function can be specified as (a) indicating the location of a referent relative to the deictic centre, and (b) coordinating speaker and addressee attention on that referent. The two conditions are inter-related: if either (a) or (b) is successful, the other condition is likely to be met, and thus there are two routes to referent identification. Note that although we have a preconceived idea of the core function of demonstratives, namely drawing attention with a gesture to a physical referent in the vicinity of the speech event, the function needs to be generalized to nonmaterial referents and non-gestural usages as in this city or this strange smell, 
where the demonstrative 'locates' the referent in the presumptive common ground of mutually assumed entities. Or if you and I are at a restaurant table with a candle in front of us, this candle coordinates attention on a mutually manifest entity (Smith, 1982) without the need for gesture or location information. In many languages there is rich information about the qualities of the referent (e.g. in Goemai, this volume, about the position and support of a referent) which may obviate locational specification. And in many languages, as reviewed below, there may be special forms reserved not for drawing attention to a referent, but for exploiting mutual awareness of it.

Even if we take the key prototype of demonstrative function as an expression with a gesture drawing attention to something in the environment, that alone will not suffice to individuate demonstratives, for it turns out that many definite referring expressions can be used in just such a way (as in What a peculiar man said pointing at a man). So demonstratives are also identified by being closedclass items that form small contrastive sets, with distinct properties of morphological combination and distribution in a clause. The form and syntax of demonstratives are of course language specific, and many details of this sort will be found within this book. Thus, it is the combination of distinctive function and a relatively small closed-class set of terms that enables recognition of a demonstrative category cross-linguistically.

\subsection{The Form and Syntax of Demonstratives}

The place of demonstratives in the pronominal field of a language varies according to whether a language has third person pronouns proper or just uses demonstratives instead, and in the latter case according to whether there are also dedicated anaphoric pronouns (not aligning with the personal pronouns), and so whether demonstratives are also employed for that function. Bhat's $(2004 ; 2013)$ typological survey of pronouns suggests that less than half of all languages have third person pronouns clearly modelled on first and second pronouns; and a third of languages base their third person (anaphoric) uses on demonstratives, sometimes derivationally, or by using a specific demonstrative (often the remote one) as an anaphoric pronoun.

Diessel (1999) provides a useful overview of the morphology and syntax of demonstratives based on a balanced sample of 85 languages. Demonstratives may be free or bound forms or clitics, they may inflect for case, or agree in gender, with a tendency for adverbial forms to be less bound and less inflected. The traditional division of demonstratives into three subclasses, demonstrative pronouns like this, demonstrative adjectives or adnominals as in this book, and demonstrative adverbs like here (location) or thus (manner) generally holds up cross-linguistically, to which a subclass of presentationals (as in French voilá!) is often added. Diessel (1999) also makes a case for a rarer additional category 
of 'demonstrative identifiers' occurring in minimal clauses serving to introduce a referent (glossing, for example, as 'This is ... '). In addition, there are verbs of 'doing like this' in many languages (Guérin, 2015). These different subclasses can be distinguished on distributional grounds, pronominals constituting an NP on their own, while adnominal demonstratives combine with a nominal phrase to constitute an NP. In about 70 per cent of languages, the pronominal and adnominal stems are the same in form (Diessel, 2013a), but in the rest they differ. Typically, pronominal and adnominal forms will differ in root form, in inflectional possibilities or syntactic distribution. Nevertheless, in some generative accounts they are both conceived to be determiners regardless - intransitive determiners in the case of demonstrative pronouns, and transitive ones in the case of adnominal ones (Abney, 1987; see Diessel, 1999: 62-71 for discussion). This raises the question as to exactly how demonstratives are to be distinguished from definite articles. Lyons (1977) has suggested that definite articles are just demonstratives unmarked for spatial distinctions, for example. But as we will see, many of the systems described in this book have neutral or unmarked demonstratives which contrast strongly in form and function with definite articles in the language in question (see, e.g., the chapter on Tzeltal). Once again, the crucial difference is semantic - the distinction between an instruction to find the referent in the context of the speech event (demonstratives) versus an instruction to find it in the universe of discourse (definite articles), a distinction often reflected in form and always in function.

The demonstratives surveyed in this book have quite different formal properties. Some are affixes as in Chukchi, which, when attached to a pronominal root, make a demonstrative pronoun, and to an adverbial or place root or simply a locative case, an adverbial. Others, as in Tzeltal and Yucatec, are circumclitics with very complex co-occurrence with stems. Some of the demonstrative roots are adverbs, which then derive pronouns, as in Jahai. Many demonstrative adnominals inflect for case, number, gender, animacy and the like, and a wide range of such types can be found in this volume.

\subsection{The Semantics of Demonstratives}

We have pointed out that deictic expressions in general get their interpretations from the context of the speech event $-I$ refers to the current speaker, now to an interval including the time of speaking and here to a location including the place of speaking (Bühler's [1934] 1982 origo). In that respect such expressions are variables waiting for further specification from the environment - they are themselves referentially under-specified. The same holds for demonstratives: this or that are instructions to find the referent in the context but give little clue about how to do this - there may be some spatial opposition (a point we will return to), and obviously identification will be 
much helped by a pointing gesture (and occasionally, in languages like Goemai, this volume, where demonstratives contain classifiers based on the referent's specific properties). In general, then, demonstratives, as with other deictics, work by being semantically general to a point that they invite the recipient to use contextual clues to find a definite interpretation. In I've hurt this finger, it is the vacuity of this that directs visual attention to the speaker's hands. Similarly, This smells bad may refer to whatever the speaker is holding up to her nose, or to the room we just walked into, or whatever is plausible in context. The kind of semantics built into demonstratives is therefore necessarily shallow.

How then is the referent recognized by the recipient? Quite largely just because a demonstrative by convention indicates that the speaker warrants that the addressee can find the referent in the context, given whatever semantic properties the particular demonstrative requires the referent to meet and other signals like gaze and gesture. How should the addressee find the referent, given the relative semantic vacuity of the demonstrative? In just the same way that Schelling Games are resolved (Schelling, 1960), by working out what the speaker thinks that the addressee thinks the speaker supposes to be the salient object of attention in the domain (see, e.g., Clark, 1996). This reflexive reasoning is reflected in the activation of the frontal lobes and the attentional and 'theory of mind' neural networks during demonstrat§ive use (Peeters, Chu, et al., 2015).

But important clues to the identity of the referent lie not only in the demonstrative chosen but also in the contrastive items not selected, and here the principles of semantic and pragmatic oppositions become salient: if that is used, the implication is that some crucial properties for the use of this did not obtain. Those properties may be built into the demonstrative semantics (e.g. this may specify spatial proximity), or they may come about by pragmatic obviation (see section 3 below): for example, that may not actually specify spatial distance but be neutral for distance, but because this was avoided (which may imply spatial proximity), that will pick up the complement of possible referents.

In this sort of way, understanding the precise semantics of demonstratives is important for understanding how they function. Where (as mostly) there are contrastive items, these must somehow divide the space of possible referents. One obvious way of doing this is by spatial zones, e.g. distinct radii around the speaker, but spatial zones can also be specified around the addressee, or around the joint space occupied by speaker and addressee. The following figure shows an idealized model of radial categories around the speaker (here the deictic origo, Bühler (1982 [1934])), a model that seems to be presumed in many grammatical descriptions. This volume throws considerable doubt on whether any language actually has a system like this. 


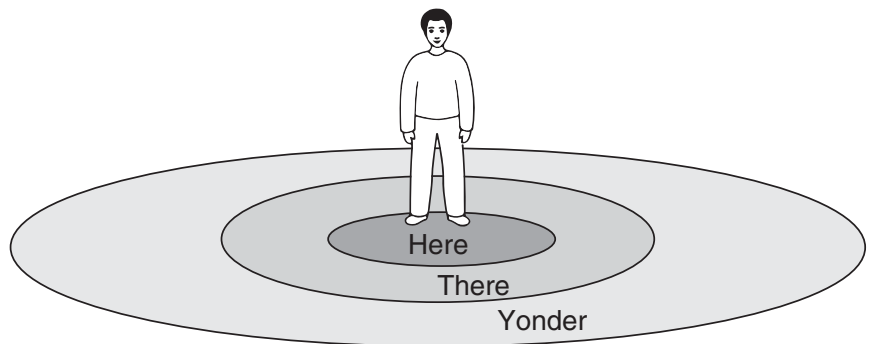

Figure 1.1 Idealized model of speaker-anchored radial spatial categories

In addition to horizontal proximity, more rarely the vertical dimension may be used to carve the search space into higher versus lower zones. These will give restricted search domains for the referent. Less obvious ways of narrowing the search domain are also possible. For example, a contrast can be made between things that are already in our joint attention, as judged by gaze, for example, and things that are now in my attention but not yet in yours. Such systems have been described for Japanese and Turkish (see, e.g., Özyürek, 1998; Küntay and Özyürek, 2002, 2006). Another distinction which occurs is between referents visible to the speaker or recipient or both versus those obscured. Many systems sometimes also specify properties of the referent, such as gender or animacy. Building on earlier work by Anderson and Keenan (1985), Fillmore (1997) and others, Diessel (1999) provides a useful overview of the kinds of contrasts that have been reported in grammars of 85 languages that span many major language families. Hanks (2009) provides a more systematic review of the underlying semantical concepts, noting that systems elaborate on variants in the origo or 'indexical ground', variants in the mode of access to the referent and various properties of the referent itself. This book supplements earlier work by going into much deeper detail on the actual nature of the contrasts encoded, albeit in a relatively small sample and with restricted methods.

Recently, there has been extensive debate on what might be called the 'spatial bias' in the description of demonstrative systems (Hanks, 2005; 2011). This (alleged or real) bias is the presumption that spatial distinctions, usually in terms of distance from the speaker, form the primary semantic axis of contrast between demonstrative items. This bias is reflected in descriptive grammars, where without much investigation demonstratives are labelled as 'proximal', 'distal', 'medial' or the like. Earlier surveys and typologies have reflected this bias in the grammatical descriptions (Halliday and Hasan, 1976; Lyons, 1977; Anderson and Keenan, 1985; Diessel, 1999; Dixon, 2003). Hanks $(1990 ; 1992 ; 2011)$ points to much more subtle interactional factors 
lying behind some systems, and rather than thinking of the distinctions being organized as constraints on search domains, he emphasizes modes of conceptual access to referents and ways of directing attention - the different modes of perception (vision, audition, etc.), inference and retrieval from memory or discourse. On this analysis, the deictic field naturally extends to anaphora and textual reference (or to endophora as well as exophora), and to an ethnographic understanding of what makes referents salient in a context (Hanks, 1990). Hanks (2011) also notes that the spatial bias has tended to be associated with an egocentric or speaker bias, and that the addressee's access to the referent can be at least as important - the one must signal but the other must grasp, and some demonstrative systems clearly utilize a distinction about where the addressee's attention currently is. Hanks argues that the origo or deictic centre, even in what are described as speaker-centric systems, may be much more open, in fact unmarked, and may routinely be addressee transposed, or inclusive of both speaker and addressee (experimental work on Spanish using similar methods to those pioneered in this book substantiates this: Coventry et al., 2008, and Jungbluth, 2003; see also Peeters, Hagoort and Özyürek, 2015 on Dutch).

Hanks' $(1990 ; 2005)$ work on Yucatec Maya, based on interactional observation, makes a compelling case for dethroning spatial distinctions (but see Bohnemeyer, this volume, on the same language). There is no doubt that an ethnographically grounded interactional perspective, sensitive to social boundaries, is essential to understanding tokens of usage. But Enfield (2003, and this volume), using interactional records, shows that in the case of Lao the same methods substantiate a spatial analysis, albeit a surprising one, in which a spatial sphere of activity or attention is crucial for a distal demonstrative, while the contrastive alternate is not a proximal demonstrative but one unmarked for location. In general, the degree to which spatial coding is crucial seems to be a language-specific matter. But what is clear is that the spatial spheres involved will always be pragmatically elastic. Here, recent work in psychology and the neurosciences is pertinent. Kemmerer (1999) carefully considered the possibility that the proximal/distal distinction so often reported in descriptions of demonstratives maps onto a neurologically determined distinction between peripersonal space and extrapersonal space (a distinction reflected in patients with spatial neglect) but rejects it on the basis that demonstrative use is far more flexible, and many demonstrative systems seem to make a three-way distinction. Coventry et al. (2008), however, show that in both English (a two-term system) and Spanish (a three-term system) usage is indeed sensitive to the peripersonal domain (roughly one's sphere of reach), and moreover, when one extends the peripersonal reach by giving participants a stick, the proximal domain increases accordingly! In English (but not in 
Dutch, see Peeters, Hagoort and Özyürek, 2015) the association of this with proximity of referent to speaker is strong enough under conditions of joint attention to elicit an N400 (a neural marker of integration difficulties during interpretation) where there is a spatial incongruency (Stevens and Zhang, 2013). Many papers in this volume report a specific notion of proximity which seems to coincide with the reaching zone, and within which proximal demonstratives may be obligatory (see discussion below and Peeters et al., 2014). And much recent experimentation supports a deep conceptual connection between spatial cognition and demonstratives (see, e.g., Coventry et al., 2014; Bonfiglioli et al., 2009). The discussion of the importance of spatial distinctions is, then, by no means over, and the chapters in this book continue the discussion.

The number of distinctions made in a demonstrative system has often been used as an organizational framework for description and typology, especially for demonstrative pronouns and adnominals (Frei, 1944; Anderson and Keenan, 1985; Diessel, 1999; Dixon, 2003). Although Anderson and Keenan (1985) describe a number of systems as having four or more degrees of spatial distance (up to seven in the case of Malagasy), Fillmore (1982) and Diessel (1999) are rightly sceptical. Nevertheless, the World Atlas of Language Structures provides some frequencies for the number of spatial distinctions in adnominals, with $c .5$ per cent of languages having four or more such distinctions (Diessel, 2013a). Hanks (2011) notes that some complex systems resist a simple radial treatment in distance from ego, requiring instead, for example, notions of laterality or exteriority (areas outside the primary space, as in West Greenlandic; see also Jahai, this volume), or distinct indexical grounds or origos, or the kind of interactional factors mentioned above. Whatever the basis of the distinctions, it is important to note that demonstrative pronouns, adnominals and adverbs may make different numbers of cuts (Hanks, 2011). English makes a binary opposition across all three grammatical sub-domains, but many languages have richer distinctions, whereas Tongan distinguishes four demonstratives in the pronouns and only two in the adnominals (Diessel, 2013a). Where the number of distinctions is the same but the forms are different across all these grammatical classes, we have a special type of lexical organization, where a parallel series of semantic oppositions is pursued across a number of form classes - a semantic template or 'semplate' (Levinson and Burenhult, 2009). All these paradigm patterns are of considerable interest, and they appear to be very stable over long periods of time, offering a window on long-range language relationships (ongoing work by Nick Evans and Simon Greenhill).

We return below to the semantics of demonstratives in the light of the chapters in this volume. 


\subsection{The Uses of Demonstratives}

The analysis of demonstratives is much complicated by the fact that they tend to get used for many different functions, some beyond strictly deictic uses, such as tracking referents in discourse. The following diagram (from Levinson, 2004) displays a complex taxonomy of different uses. A first cut can be made between the deictic and non-deictic uses, of which anaphora is the most important: that man has a different role when used to point someone out than it has when embedded in a text like I was introduced to Mr Little: That man was to have a huge influence on my fortunes. The distinction is usually made more coarsely in terms of exophoric (external to the text) versus endophoric (textinternal) uses, but, as Fillmore (1997) pointed out, one needs to distinguish anaphora, where a term simply picks up the same reference as a prior term, from discourse deixis, where a term refers to a chunk of discourse itself, as in Bloop! It sounded like that. There are additional non-deictic uses like the empathetic that goddamn son of a bitch (see the chapter on Dalabon, this volume, and Naruoka, 2006) or the recognitional uses (Himmelmann, 1996) as in Do you remember that wonderful holiday in Morocco?

Within the exophoric uses, one needs to distinguish those expressions (gestural uses) that require a gesture (as in This eye hurts) from those that don't (symbolic uses as in This room is beautiful). Notice that, contrary to some remarks in the literature (e.g., Diessel, 2014), many uses of demonstratives do not require gestures, and much of this book is concerned with those uses. Where gestures occur, the kind of gesture required may vary, from a head nod or lip point, to a marked gaze, to a manual point, or to a demonstration (This finger hurts). The shape of the hand and its orientation can also be

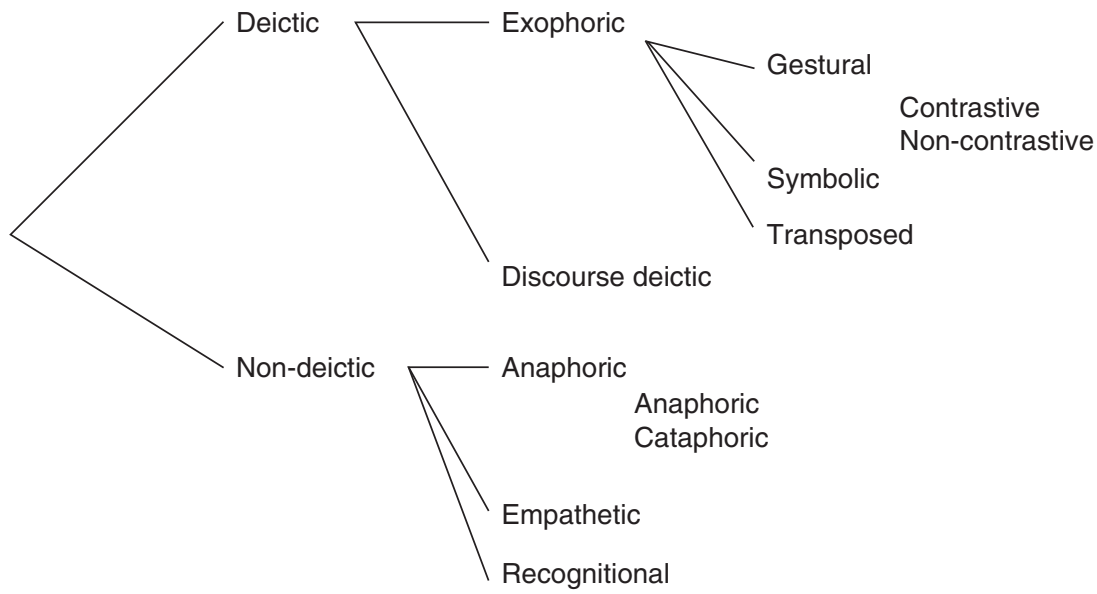

Figure 1.2 The distinct uses of demonstratives (after Levinson, 2004) 
distinctive - The motion in He went that way is more likely to be accompanied by a lax hand than an index finger point. Contrastive uses of demonstratives are also distinctive, as in This mug is larger than that one, versus non-contrastive uses It's hard to read in this light (see section 2.2.2.3 below).

One celebrated property of deixis is its ability to be transposed (Bühler, [1934] 1982), especially in a narrative context, to some other time and place, as in This was the book he needed, John realized, where the origo is not in the situation of utterance but transferred to the narrative event (see also Fillmore, 1997). Many uses of demonstratives are transposed, and part of the uncertainty of analysis may lie in whether a deictic ground (origo or anchor) is basically speaker-centric and transposed to the addressee (This is your glass pointing at the glass nearer to you), or whether it includes both perspectives to start with.

Another kind of usage distinction cross-cutting the exophoric uses above is a distinction between a referent already in the addressee's attention versus a referent that is not yet so. As mentioned at the outset, a key function of demonstratives is to draw the addressee's attention to an object or event in the immediate environment. Once attention is drawn further reference can often be made with a demonstrative, but sometimes of different form, as is required in Turkish (Küntay and Özyürek, 2006) and some of the languages discussed in this volume (e.g. Jahai, Yucatec, Tzeltal).

English demonstrative pronouns like this and that can occur across all these distinctive usage types. But many languages have forms specially reserved for some of these functions. For example, many languages have special anaphoric pronouns of distinctive form. Some demonstratives are specialized to gestural uses, as in yay big in American English, or to manner adverbials glossing 'thus, (do) like this'. These distinctions are important for the proper study of demonstratives across languages (König, 2012; Umbach and Gust, 2014; van der Auwera and Sahoo, 2015).

It is generally agreed that the exophoric uses (and specifically the gestural ones) are primary and prototypical. The reasoning for this is that, first, these are the earliest learned forms and usages in language acquisition. Second, these uses are probably the most frequent in daily interaction (although not of course in text corpora) and tend to be the unmarked usages, the default interpretations. Third, they would seem to be diachronic sources for other grammatical items, and indeed for the anaphoric uses of the same forms. This book is focused on these exophoric uses.

\section{2}

\section{The Current Volume}

This volume differs from earlier typological surveys of demonstratives in that it is not based on extracting cross-linguistic generalizations from existing grammars or descriptions. It aims instead for a deeper understanding of meaning and usage in a small but widely dispersed sample of languages, so probing for some 
of the key parameters of world-wide variation (a similar but European-based survey can be found in Da Milano, 2005). As already mentioned, the chapters in this volume have a common framework, namely a uniform task that was conducted in the field by each of the contributing authors. The task was designed to get beyond the simple and usually inaccurate 'proximal versus distal' kind of accounts of demonstratives. It is also designed to resolve the kinds of controversies about the correct analysis of systems that can be found in the literature, as, for example, the treatment of Turkish as having a speakeranchored proximal versus distal (Kornfilt, 1997) or a speaker-anchored versus addressee-anchored system (Lyons, 1977) or one primarily concerned with attentional factors (Küntay and Özyürek, 2002).

The chapters review the nature of demonstratives in 15 languages, drawn from 14 language families or isolates from all the major continents, and many different kinds of social and subsistence systems (there have been speculations that demonstrative systems might be linked to such social variables; see Perkins, 1992). This is a well-dispersed sample, which should reveal any clear universal structure, while indicating directions of linguistic variation. Table 1.1 provides a summary of the languages, in the order in which they are described in this book.

The following sections of the introduction describe the task and explore some of the main results that have emerged from the comparative exercise.

\subsection{The Task}

All the authors in this volume took a particular elicitation instrument to the field designed for the purpose, David Wilkins' (1999a) 'Demonstrative questionnaire: "THIS" and "THAT" in comparative perspective' (included here as Chapter 2). As the title makes clear, this was quite restricted in scope, aimed at the demonstrative pronouns and adnominal demonstratives in particular, although supplemented by other instruments (particularly 'Eliciting contrastive use of demonstratives for objects within close personal space' of the same date (1999b)). The title is, however, a bit misleading, as the instrument is not a straightforward questionnaire; rather, it describes a task to be carried out in elicitation sessions with (preferably) five or more native speakers in their natural ecology, where scenes are to be enacted or played out in local settings, improvising the relevant interactions. Different scenes are described (with a numbered sketch as a mnemonic) with different locations of speaker, a single addressee and a referent, and the fieldworker attempts to re-enact the scene with native speakers. ${ }^{3}$ English sentential frames were given as

3 A similar, and derivative, questionnaire can be found in Da Milano (2005), where the emphasis is on different sentence and speech act frames; it was used in a European survey, where translational equivalents are easier to find. 
Table 1.1 The languages surveyed in this volume

\begin{tabular}{|c|c|c|c|c|c|}
\hline $\begin{array}{l}\text { Language } \\
\text { name }\end{array}$ & $\begin{array}{l}\text { Glottolog } \\
\text { reference }\end{array}$ & $\begin{array}{l}\text { Language } \\
\text { family }\end{array}$ & Location & Subsistence type & Researcher \\
\hline Lao & laoo 1244 & Tai-Kadai & Laos & $\begin{array}{l}\text { Rice growing, } \\
\text { market economy }\end{array}$ & Nick Enfield \\
\hline Dalabon & ngal1292 & Gunwinyguan & $\begin{array}{l}\text { Arnhem } \\
\text { Land, } \\
\text { Australia }\end{array}$ & Hunter-gatherer & Sarah Cutfield \\
\hline $\begin{array}{l}\text { Brazilian } \\
\text { Portuguese }\end{array}$ & braz1247 & $\begin{array}{l}\text { Indo- } \\
\text { European }\end{array}$ & Brazil & $\begin{array}{l}\text { Urban and rural } \\
\text { industrial state }\end{array}$ & $\begin{array}{l}\text { Sérgio Meira \& } \\
\text { Raquel } \\
\text { Guirardello- } \\
\text { Damian }\end{array}$ \\
\hline Goemai & goem 1240 & Afro-Asiatic & Nigeria & Horticulturalists & Birgit Hellwig \\
\hline Tzeltal & tzel1254 & Mayan & Mexico & $\begin{array}{l}\text { Slash and burn } \\
\text { cultivators, } \\
\text { market economy }\end{array}$ & $\begin{array}{l}\text { Penelope } \\
\text { Brown, } \\
\text { Stephen } \\
\text { Levinson }\end{array}$ \\
\hline Yucatec & yuca1254 & Mayan & Mexico & Slash and burn & Jürgen \\
\hline Maya & & & & $\begin{array}{l}\text { cultivators, } \\
\text { market economy }\end{array}$ & Bohnemeyer \\
\hline Lavukaleve & Lavu1241 & Isolate & Solomons & Horticulturalists & Angela Terrill \\
\hline Tiriyó & trio1238 & Cariban & $\begin{array}{l}\text { Brazil, } \\
\text { Surinam }\end{array}$ & Horticulturalists & Sérgio Meira \\
\hline Trumai & trum 1247 & Isolate & $\begin{array}{l}\text { Xingu, } \\
\text { Brazil }\end{array}$ & Horticulturalists & $\begin{array}{l}\text { Raquel } \\
\text { Guirardello- } \\
\text { Damian }\end{array}$ \\
\hline Saliba & sali1295 & Austronesian & $\begin{array}{l}\text { Papua New } \\
\text { Guinea }\end{array}$ & $\begin{array}{l}\text { Fishers, } \\
\text { horticulturalists }\end{array}$ & Anna Margetts \\
\hline Warao & Wara1303 & isolate & $\begin{array}{l}\text { Venezuela, } \\
\text { Guyana }\end{array}$ & $\begin{array}{l}\text { Fishers, } \\
\text { horticulturalists }\end{array}$ & $\begin{array}{l}\text { Stefanie } \\
\text { Herrmann }\end{array}$ \\
\hline Chukchi & chuk1273 & $\begin{array}{l}\text { Chukotko- } \\
\text { Kamchatkan }\end{array}$ & $\begin{array}{l}\text { S Siberia, } \\
\text { Russia }\end{array}$ & $\begin{array}{l}\text { Hunter-gatherers, } \\
\text { reindeer herders }\end{array}$ & Michael Dunn \\
\hline Yélî Dnye & yele 1255 & Isolate & $\begin{array}{l}\text { Papua New } \\
\text { Guinea }\end{array}$ & $\begin{array}{l}\text { Fishers, } \\
\text { horticulturalists }\end{array}$ & $\begin{array}{l}\text { Stephen } \\
\text { Levinson }\end{array}$ \\
\hline Tidore & tido 1248 & $\begin{array}{l}\text { North } \\
\text { Halmaheran } \\
\text { (West Papuan) }\end{array}$ & $\begin{array}{l}\text { Tidore } \\
\text { island, } \\
\text { Indonesia }\end{array}$ & $\begin{array}{l}\text { Horticulturalists, } \\
\text { traders }\end{array}$ & $\begin{array}{l}\text { Miriam van } \\
\text { Staden }\end{array}$ \\
\hline Jahai & jeha1242 & Austro-Asiatic & Malaysia & Hunter-gatherers & $\begin{array}{l}\text { Niclas } \\
\text { Burenhult }\end{array}$ \\
\hline
\end{tabular}

examples to the fieldworker, but this was not a translation exercise - the aim was to contrive a situation in which the native speaker could role-play and volunteer the relevant demonstrative. Investigators were also encouraged to keep a lookout for naturally occurring instantiations of the same or similar arrangements. Scene 6, for example, reads: 
The referent is just beside speaker (within easy reach), on side away from addressee: The object is difficult, if not impossible for addressee to see. 'I've just finished reading book.' 'Do you want to borrow book?'

- Does it make a difference if Addr knows the object is there vs doesn't know?

- Does it make a difference if object has been mentioned before?

- Must the speaker point?

- What if object was more visible?

Each of the 25 scenes thus invokes many parameters, attempting to control not just spatial parameters but also the nature of the setting (bounded or unbounded), the relative locations of speaker, addressee and referent and sometimes a bystander, the current attentional focus of speaker and addressee, whether the referent has been mentioned earlier in the interaction, the presence or absence of accompanying gesture and so forth. The scenes vary the distances between speaker, addressee and referent on an implicit seven-point scale (from speaker's body part, referent touching body part, reaching distance, a couple of steps away, tens versus hundreds of metres away, to horizon).

The scenes are not presented pictorially to consultants, the figures being merely an aid for the fieldworker; rather, as mentioned, they are acted out. The fieldworker therefore has to 'localize' the scenes, finding a local instantiation that closely matches the described situation in its pertinent aspects and attempting to act it out on a corresponding scale. By getting multiple consultants to do the same task, one is able to factor out personal differences, or differences in construal of the scene that might otherwise be misleading. The task was particularly focused on exploring different indexical grounds (e.g. speaker or addressee as origo), possible distance distinctions, the role of visibility or access to the referent, together with the role of gesture and attention. To be precise, the kinds of demonstrative pronoun use in focus here are exophoric ( $+/-$ gestural), non-contrastive uses (the contrastive use being explored in the other instrument just mentioned). The task was reasonably demanding to run, as it involved putting participants in different locations, sometimes at rather great remove from speaker or referent, and could best be done with an assistant, taking some hours to run through.

Such a task is of course limited, but it in fact yields information of a kind difficult to get in any other way. Missing from the task, for example, was any probing for 'such' or 'like this' demonstratives (König, 2012). Fieldworkers were urged to amplify the information by using additional tasks, noting informal usage around them and examining videotapes of natural interaction - as Hanks (2011), Jungbluth (2003) and Enfield (2003) have emphasized, natural interactional usage is critical to understanding these systems (and in fact information on 'like this' demonstratives will be found in, for example, the Tzeltal chapter). But one excellent payoff from administering the task is much 
greater clarity about the relevant demonstrative systems than in preceding accounts. For example, the Venezuelan indigenous language Warao, described by Herrmann in this volume, has previously been described as a personoriented system, or as a two-way speaker-proximal versus distal system, while in fact it turns out to basically introduce a three-way contrast within speaker's reach, outside speaker's reach and way beyond. In the case of Yucatec, the account here by Bohnemeyer based on the task yields a different account from the well-known analysis by Hanks $(1990,2005)$ based on ethnographic observation, specifically showing that an addressee-anchoring is doubtful. In a number of other languages, the authors themselves had held different views before administering the task (see, e.g., the chapters on Trumai, Lavukaleve, Jahai, Tidore or Tzeltal).

The task was constructed subsequent to the publication of Hanks' (1990) interactional account of Yucatec demonstratives based on dense ethnographic observation, and attempted to capture some of the variables he had noted. However, interactional analyses yield complementary data, and it is interesting to compare descriptions obtained by both means: sometimes the accounts converge (cf. Enfield, 2003 and this volume), but sometimes they diverge (cf. the accounts of Yucatec given by Hanks, 1990, and Bohnemeyer, 2012 and this volume).

\section{$2.2 \quad$ Some Results}

The first impression of the demonstrative systems here sampled from the world's languages is one of overwhelming diversity. They differ in their formal exponents - whether they are affixes, clitics or free forms, whether they are fundamentally nominal, adverbial or otherwise. They differ in whether they form a neat paradigm, for example whether the demonstrative pronouns make the same number and nature of distinctions as the adverbs, or otherwise. They differ in their semantics - whether, for example, they are centred on speaker, addressee or both, or whether they delimit definitive spatial extensions or something more complex. They differ in their range of usage, for example whether the same form is used for exophoric and anaphoric reference or whether dedicated anaphoric forms form part of the paradigm; or whether the forms require a gesture or one is merely optional; or whether they presume shared attention on a referent or create it. What, however, they share in common is a core function - namely the identification of a referent (or place) in the shared environment of the speech event by appeal to a Schelling-like presumption that recognition can be achieved (see Clark, 1996: 62f.), aided by any gestural (and gaze) indications and semantic specification inherent in the forms. 


\subsubsection{Form and Function}

Since Frei (1944), the typology of demonstratives has often been laid out in terms of the number of opposing terms employed - thus two-term, three-term and multi-term systems (see, e.g. Anderson and Keenan, 1985; Diessel, 1999). But this is misleading for a number of reasons. First, there is confusion about whether distinctions made in the adverbs should enter the count - Diessel (1999) considers that they should and so denies the existence of one-term demonstrative systems, even though his native German has only one clear demonstrative pronoun. Incidentally, in this introduction we will use the term demonstrative to refer to pronominal or adnominal forms, specifying 'demonstrative adverb' when that is what is meant. Second, there is unclarity about whether the count is the number of terms in the paradigm (and if so, whether it includes or excludes dedicated anaphorics), or the number of underlying semantic distinctions. For example, Diessel (2013b) counts what he takes to be just the semantically encoded distance distinctions in 234 languages and finds that 54 per cent of languages make two such distinctions, 38 per cent make three such distinctions, 3 per cent make four distinctions and 2 per cent make five distinctions. This information is based on grammars, which tend to use a 'proximal'/'distal' terminology by default rather than by careful examination - as we have seen, authors of grammars who have used the demonstrative task often find themselves to have been wrong.

The semantic distinctions of relevance may be restricted to spatial distance only or include additional deictic factors (e.g. attention, visibility, direction) or include properties of the referent (e.g. number/gender/animacy) and more exotic distinctions. For example, Goemai is only a two-term system if one abstracts out the deictic prefixes from the pronominal forms - if not, it is a system with 36 pronominal forms, made up of combinations of the nine positional classifier roots, two numbers and the two demonstrative forms. Clearly, for languages where the demonstratives are primarily affixes or clitics (e.g. Goemai, Tzeltal, Yucatec in this book), the forms will tend to multiply according to which items they are attached to in order to form demonstrative pronouns. In many languages, e.g. Brazilian Portuguese, pronominals typically occur with adverbials (which in this case make more deictic distinctions than the pronominals) on the pattern of 'this here' - there are eight such phrasal combinations, plus six independent forms, so 14 in total (see also Jungbluth and Da Milano, 2015).

Table 1.2 shows, for the languages in this book, how these different ways of counting do not align. The numbers should be taken with caution, since what is a 'deictic feature' is contestable, and not all authors spell out all the possibilities, concentrating on forms central to their analyses. Dedicated anaphoric terms within the demonstrative paradigm are here treated separately, and 
Table 1.2 Numbers of deictic distinctions versus numbers of terms in pronominal/adnominal demonstratives in the languages in this volume

\begin{tabular}{|c|c|c|c|c|c|}
\hline Language & $\begin{array}{l}\text { Main } \\
\text { deictic } \\
\text { semantic } \\
\text { distinctions } \\
\text { in nominals }\end{array}$ & $\begin{array}{l}\text { Distinct } \\
\text { demonstrative } \\
\text { pronominal } \\
\text { forms }\end{array}$ & $\begin{array}{l}\text { Non-deictic } \\
\text { semantic } \\
\text { distinctions in } \\
\text { pronominals }\end{array}$ & $\begin{array}{l}\text { Additional } \\
\text { dedicated } \\
\text { anaphoric } \\
\text { demonstrative } \\
\text { morpheme(s)* }\end{array}$ & $\begin{array}{l}\text { Adverbial } \\
\text { forms (in } \\
\text { brackets } \\
\text { additional } \\
\text { dedicated } \\
\text { anaphoric } \\
\text { forms) }\end{array}$ \\
\hline Lao & 2 & 2 & 0 & 0 & 2 \\
\hline Goemai & 2 & 36 & $\begin{array}{l}\text { Number (2), } \\
\text { Posture (9) }\end{array}$ & 1 & $2(+1)$ \\
\hline Yucatec & 2 & over 18 & Various & 1 & 4 \\
\hline Tzeltal & 3 & over 22 & Various & 0 & $3(+1)$ \\
\hline Warao & 3 & 11 & $\begin{array}{l}\text { Location, } \\
\text { Existence, } \\
\text { Number, } \\
\text { Subordination }\end{array}$ & 1 & 3 \\
\hline $\begin{array}{l}\text { Brazilian } \\
\text { Portuguese }\end{array}$ & 3 & $\begin{array}{l}6 \text { (14 including } \\
\text { Adverbial } \\
\text { combinations) }\end{array}$ & Gender & 1 & 4 \\
\hline Saliba & 3 & 3 & 0 & 1 & \\
\hline Trumai & 3 & 18 & $\begin{array}{l}\text { Gender, } \\
\text { Number }\end{array}$ & $+?$ & 3 \\
\hline Tiriyó & 4 & 18 & $\begin{array}{l}\text { Animacy, } \\
\text { Number }\end{array}$ & 4 & 4 \\
\hline Dalabon & 4 & 5 & 0 & + & 2 \\
\hline Chukchi & 4 & $4(*$ cases $)$ & 4 & $?$ & $4 * 3$ cases \\
\hline Lavukaleve & 4 & 28 & $\begin{array}{l}\text { Number, } \\
\text { Gender }\end{array}$ & + & $?$ \\
\hline Yélî & 5 & 5 & 0 & 1 & $4(+1)$ \\
\hline Tidore & 7 & 7 & 0 & $?$ & 7 (verbal) \\
\hline Jahai & 9 & 9 & & 0 & 9 \\
\hline
\end{tabular}

* ' + ' indicates that there are at least some dedicated anaphorics; '?' marks uncertainty in the description

systems with composite pronouns resist easy classification. The table compares nominal to adverbial forms, but the pronominals are in many cases formed from an adnominal in combination with, for example, a semantically general nominal. Note from the table that many systems have large numbers of forms generated by number, gender and other distinctions, so the mean number of pronominal forms is around 13 for this sample. The Tzeltal and Yucatec cases are harder to classify, since they have multiple forms compounded from different deictic elements. 
Table 1.2 makes clear that there is no simple relation between the number of forms and the number of deictic distinctions. Clearly the added information about number, gender, animacy and the like - what Diessel (1999) calls qualities of the referent - may help to identify the referent and proliferate forms. The Goemai posture information, specifying whether the referent is hanging, standing, sitting or lying, is clearly very helpful in this regard and is in a sense spatial and classificatory, but not deictic.

These referent properties are one way to aid recognition of the referent. But there are many others. Let us discount the specific semantic specifications of properties of the referent and consider just purely deictic properties - parameters that make essential reference to the properties of the speech event rather than the referent. These are, on a first approximation, the properties enumerated in the first column of Table 1.2. An interesting question is what are these, and to what extent do they follow a predictable typology of distinctions - for example, the radial distances presumed in the sources used by Diessel (2013b). We discuss these issues in section 2.2.2 below.

\section{Paradigmatic Oppositions}

If we set aside the formal distinctions to do with properties or qualities of the referent (number, gender, animacy, positional orientation, etc.) and just look at the deictic distinctions, we can compare the numbers of distinctions (regardless of semantic basis) in pronominal versus adverbial demonstratives. What we see here (comparing columns 2 and 6 in Table 1.2) is that in some cases (Chukchi, Yélî, Jahai, Goemai, Warao, Saliba, Trumai, Lavukaleve) there seem to be the same number of pronominals as adverbials, often because the one set is derived from the other. Thus Jahai makes nine oppositions in each field. In other cases though (Lao, Yucatek, Tzeltal, Brazilian Portuguese), there is a mismatch, and this can play a significant role in usage patterns. For example, Table 1.3 shows a relatively frequent type of mismatch.

Where this kind of formal paradigm mismatch exists, it is very common for the pronominals to be reinforced with an adverbial since the adverbials add

Table 1.3 A typical paradigm mismatch ('proximal' and 'distal' are here merely indicative labels - the content may be various)

\begin{tabular}{ll}
\hline \hline Pronominals & Adverbials \\
\hline 'proximal' & 'proximal' \\
'distal' & 'distal' \\
& 'far distal' \\
\hline \hline
\end{tabular}


information - indeed, in Brazilian Portuguese usages such as esse acqui 'this here' are the norm, and single pronominals the exception (thus although the language has just two demonstratives, in combination with four demonstrative adverbs six distinctions are actually made). A similar pattern is found in Tzeltal with a binary opposition reinforced by a ternary one, as in tey a mene, "that over there', although adverbial reinforcement is less required. Lao also has the same abstract paradigm pattern, but the adverbs do not seem to play the same supporting role (see Enfield, 2003 and this volume). There are other ways in which adverbial distinctions may outnumber nominal or adnominal ones, for example where there are two sets of adverbials making orthogonal distinctions (as in Hanks' 1990 account of Yucatec; see Bohnemeyer, this volume). The reverse pattern, where there are more pronominal forms than adverbial ones, appears to be rarer. Dalabon (this volume) may appear to be a case of this sort, but in fact there are additional adverbial forms not yet fully researched (Sarah Cutfield, p.c.).

\subsubsection{Semantic Distinctions}

\subsubsection{1 'Distance': Proximity and Origin}

The literature has made much of 'distance' distinctions in demonstratives, from Frei (1944), through Anderson and Keenan (1985) to Diessel (2013b). What is actually discussed, though, is proximity to speaker or addressee or both, and thus both proximity and origo (indexical ground). The majority of the systems in this book are entirely speaker anchored, but some have both speakeranchored and addressee-anchored terms (e.g. Trumai, Saliba, Yélî Dnye, Jahai), and others only speaker-and-addressee-centred terms (Goemai and Brazilian Portuguese), an anchorage that other languages have only in the distal forms (e.g. Trumai, Saliba). One of the few plausible implicational 'universal' hypotheses emerging from this book is that the possession of an addresseeanchored term implies the possession of a speaker-based one.

The chapters in this book show that proximity is an elastic notion, and according to each language, it has different extents depending on multiple pragmatic factors, well described, for example, in the chapter on Lao (see also Enfield, 2003). There is no doubt that a notion of current interactional space is involved, and hence the location of the addressee makes a difference to the shape of the space even in systems that have no addressee-anchored form. Some recurrent factors noted in the chapters are as follows: (a) pointing enlarges the proximal space considerably (see, e.g., chapters on Lavukaleve and Tzeltal); (b) even within speaker-anchored systems, the relatively distal location of the addressee may expand the notion of proximal; (c) areas within reach of speaker and addressee tend to be treated specially (e.g., a speakeranchored or addressee-anchored proximal may then be strongly pre-emptive 


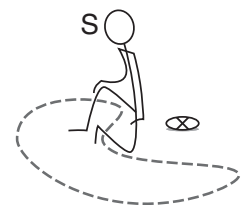

Figure 1.3 Cardioid shape of proximal space in some languages

over a neutral or unmarked term); (d) when a referent is proximal but right behind the speaker, a speaker-anchored proximal term often cannot be used, suggesting a cardioid shape to the proximal space (see, e.g., Warao, Tiriyó, Goemai, Brazilian Portuguese, Tidore and Jahai chapters, but note this is not so for Lavukaleve or Yucatec); (e) contrastive usage often neutralizes proximity. In addition to these specific factors, many social interactional factors intervene to help define a 'near space' or interactional zone, from a distal space outside that zone.

We may begin by demonstrating the utility of the questionnaire for addressing these issues on familiar European languages (they are not included in the volume here, with the exception of Brazilian Portuguese, since there is already significant literature available). The studies were done by colleagues at the Max Planck Institute for Psycholinguistics. ${ }^{4}$ Taking a selection of eight scenes in the questionnaire which map roughly onto a spatial distance metric from the speaker's point of view, we can illustrate the different extensional range of a 'proximal' and 'distal' deictic in five European languages (English, Dutch, Italian, Russian and Brazilian Portuguese) - see Figure 1.4.

In this array of languages, only Italian looks anything like the textbook or grammar book system of a neat carving of space into a speaker-anchored proximal versus distal sphere (see Bonfiglioli et al., 2009). A couple of observations can immediately be made: (1) these languages have contrasting extensions for their 'proximal' versus 'distal' demonstratives. Interestingly even closely related English and Dutch show small differences. (2) Many of the systems show significant overlap in the use of the two terms: English and Dutch permit the distal demonstrative just about everywhere (dotted lines indicate possible if less-preferred use), while in contrast Russian permits the proximal just about everywhere. (3) Brazilian Portuguese usage shows discontinuities over this speaker-anchored distance measure, with a proximal use just where the referent is far from the speaker but close to the addressee. This points to some sort of addressee anchoring (see also Meira, 2003; this volume). This shows immediately the importance of what Hanks (2011) called the

${ }^{4}$ We thank David Wilkins for English and Italian, Mariet Verhelst and others for Dutch, Michael Dunn for Russian, Sérgio Meira for Brazilian Portuguese (see Chapter 10). 

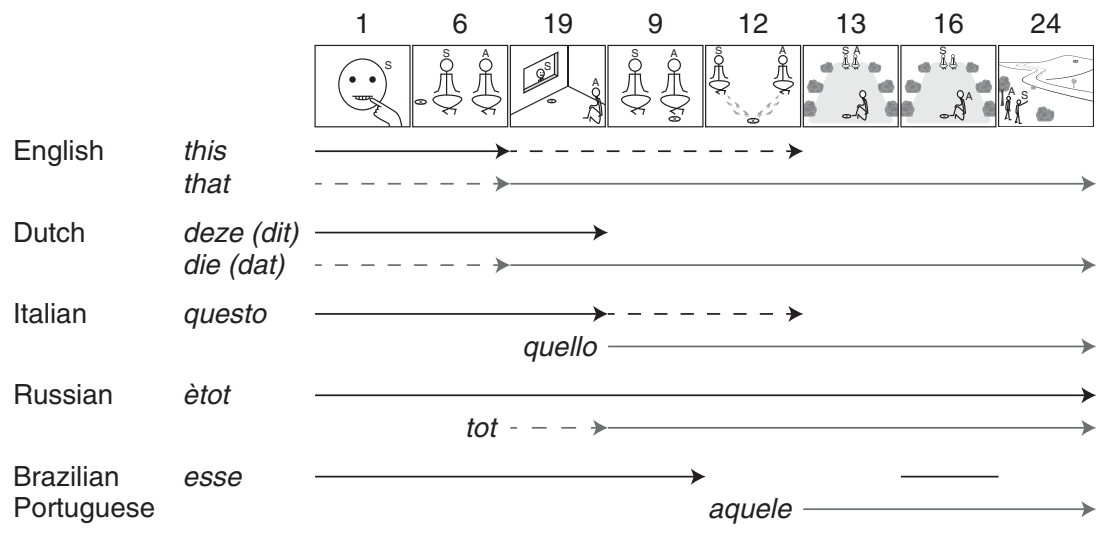

Figure 1.4 Extensions of demonstratives in some European languages (in the scenes, $\mathrm{S}$ labels speaker, $\mathrm{A}$ addressee and $\mathrm{X}$ the referent where not clear)

indexical ground, or the anchorage of the distance (or other) measures involved.

These extensional patterns are clues to the underlying intensions or abstract meanings. We will argue below, for example, that where a term may be used indiscriminately over a wide range of scenes, it is likely to be an unmarked (semantically general) term in a privative opposition. So, for example, the fact that English that can be used for referents close to the speaker suggests that it is actually unmarked for distance but picks up its distal meanings by pragmatic opposition to a marked proximal item, this. ${ }^{5}$ The mechanism here is a wellunderstood application of Gricean conversational principles, which enjoin the use of a more specific term if it applies - if the more specific term is not used, that conversationally implicates that it doesn't apply (Levinson, 2000). Russian then would be the inverse case, with an unmarked proximal, and a more specific distal which tends to restrict the meaning of the unmarked term. These conversational inferences are, like all conversational implicatures, defeasible, so in circumstances in which it is not misleading the less specific term may still be used where the specific would otherwise be expected. This yields some of the flexibility that makes the precise description of demonstratives rather hard.

Let us now pursue the other two-term pronominal/adnominal systems which are investigated in this book (we will see that this categorization is misleading in a moment). If we compare the systems of Lao (Tai-Kadai family, South-East Asia) and Goemai (West Chadic, Nigeria), we see they look different yet again

5 As can be expected, there are different analyses of the English demonstratives, with some presuming this is the semantically unmarked part of the opposition (e.g., Dixon, 2003: 81) see discussion in Enfield (this volume). 
Lao

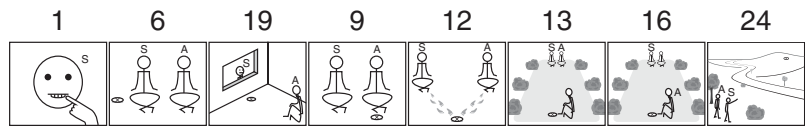

$$
n i i^{4}
$$

nan 4

\section{Goemai \\ ńd'éńnòe ńd'énáng}

Yucatec

$$
\begin{aligned}
& -a^{\prime} \\
& -o^{\prime}
\end{aligned}
$$

Figure 1.5 Some two-term oppositions in this book

(Figure 1.5). In Lao, both the proximal and the distal have large potential extensions, with just the closest and most distant scenes requiring the proximal and distal respectively. Again this suggests a system with pragmatic pre-emption, but one has to turn to much further detail to extract a clear analysis of the intrinsic meaning of the terms. In fact, for Lao the underlying semantics seems to be that the distal form $\operatorname{nan}^{4}$ carries the marked semantic content 'referent not here', while $n i i^{4}$ is unmarked, picking up the residue, and can refer to all but the most distant referents. Goemai, on the other hand, appears to have both marked proximal and distal terms, but they are both from a shared speaker and addressee anchorage - thus something can be 'near' to a distant addressee and still get the proximal term (as in scene 16 in Figure 1.5 below). Interestingly, this kind of 'we-thinking' is now recognized to play a role in other kinds of joint activity (Galotti and Frith, 2013), and especially in reference, viewed as a joint activity (Bangerter and Clark, 2003; Peeters and Özyürek, 2016).

Yucatec seems to offer the inverse to Lao - that is to say, the distal (or "nonimmediate') form seems to be unmarked and the proximal marked (cf. Russian and English above), a pattern that seems to be the more general.

We turn now to consider a bit more systematically the distinctions found in the 15 languages in this book. Table 1.4 tabulates the major types of spatial distinctions. It should be noted at once that two languages (Jahai, Tidore) have important spatial distinctions of another kind, namely directional systems making reference to, inter alia, geographical features. These will be discussed later. Setting these extra-spatial distinctions aside, the systems differ on three main dimensions:

(i) the origo or anchorage (Hanks' 2009 'indexical ground'): terms may be anchored on the speaker, the addressee or both.

(ii) zones around the anchors - here glossed proximal, distal or far distal.

(iii) the possession of a spatially neutral or unmarked term that contrasts with the terms which have a clear anchorage and a clear zone of application. 
Table 1.4 Major types of spatial distinction in the nominal demonstratives of the 15 languages, where $1=$ attested

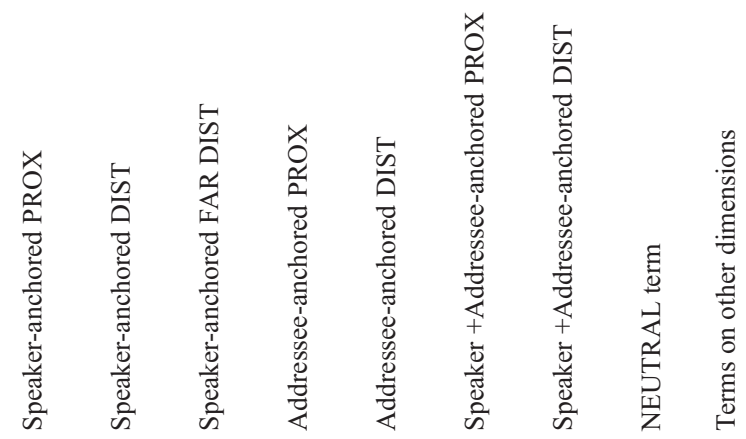

\begin{tabular}{|c|c|c|c|c|c|c|c|c|c|}
\hline Yélî Dnye & 1 & 1 & & 1 & & & & 1 & epistemic \\
\hline Chukchi & 1 & 1 & 1 & & & & & 1 & attention \\
\hline Lavukaleve & 1 & 1 & & & & & & 1 & \\
\hline Saliba & 1 & & & 1 & & & 1 & & \\
\hline Lao & & 1 & & & & & & 1 & \\
\hline Yucatec & 1 & & & & & & & 1 & attention \\
\hline Tiriyó & 1 & 1 & 1 & & & & & & new/old, auditory \\
\hline Trumai & 1 & & & 1 & & & 1 & & \\
\hline Tzeltal & 1 & & 1 & & & & & & \\
\hline Portuguese & & & & & & 1 & 1 & & \\
\hline Warao & 1 & 1 & 1 & & & & & 1 & \\
\hline Goemai & & & & & & 1 & 1 & & \\
\hline Tidore & 1 & & 1 & & & & & 1 & geocentric \\
\hline Jahai & 1 & 1 & & 1 & 1 & & & & geocentric \\
\hline Dalabon & 1 & 1 & & & & & & & $\begin{array}{l}\text { identifiable vs } \\
\text { unfamiliar }\end{array}$ \\
\hline
\end{tabular}

As an example, consider Yélî Dnye, which has speaker-anchored proximal and distal terms, an addressee-anchored term and an unmarked or neutral term (and a dedicated anaphoric term). Figure 1.6 may help to explain such a system: the diagram illustrates that referents very close to $\mathrm{S}$, those significantly distant from $\mathrm{S}$ and those very close to A all have preferred terms, but that the unmarked or neutral form has general extension, so particularly picks up the middle ground where the other terms do not apply.

The importance of these neutral terms is one of the major discoveries of this volume, occurring in half of the languages. It is also possible that the distal terms in Saliba, Tzeltal and Dalabon may better be analysed as neutral terms, because they have very wide extensions overlapping with the other terms, in which case this would be a majority encoding strategy. In the case of Tiriyó, 


\section{Kî (unmarked/neutral)}

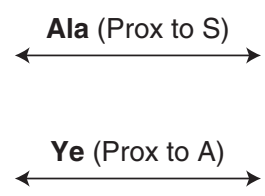

Figure 1.6 Unmarked versus marked oppositions in Yélî Dnye demonstratives

special contrastive uses suggest that the term in question is an unmarked distal, whereas in Lavukaleve it is a true neutral unmarked for proximity (Meira and Terrill, 2005). The analysis, sketched above, is that by Grice's maxim of Quantity, a speaker should use the most informative expression which applies. Thus in Yélî Dnye, if the object is in reach of the speaker, or conversely of the addressee, or alternatively in the far distance, then those more specific terms should be used; otherwise the unmarked term may be used. This explains the wide range of potential usage of the unmarked term in this language, as in the others described here, it being not strictly incorrect but potentially misleading to use it where the more specific terms apply. A possible problem for this analysis (discussed by Bohnemeyer, this volume) is that, especially for speaker-proximal or far-distal referents, it sometimes seems impossible to replace them with the neutral term. Here a comparison with temporal deixis may be helpful: if tomorrow is Friday, then it would be very odd to refer to tomorrow as 'Friday', because 'tomorrow' strongly preempts it. Deictic pre-emption is peculiarly strong. Similarly, the first person pronoun pre-empts the use of one's own name - it would be odd in normal circumstances for Anne to say "Anne thinks that a better solution is Anne's". Nevertheless, in the right circumstances, for example answering the phone, Joe can say "Joe speaking", so there is no grammatical or semantic impediment, rather a usage pre-emption.

On the basis of the findings in this volume, there are grounds to be suspicious of reports of 'medial' terms - that is to say, systems with a three-way distance contrast. Instead, it seems likely that many of these are actually two terms with clear codings for proximal and distal, and then a third term that is unmarked, or relatively unmarked. There are at least three ways this may come about, shown in Figure 1.7, and the volume clearly attests two of them.

With this preamble, we can show the similarities and differences between the systems by using the kinds of diagrams in Figures 1.6 and 1.7 above to sketch the nature of the spatial and anchorage oppositions in the main nominal 
(a) e.g. Lavukaleve

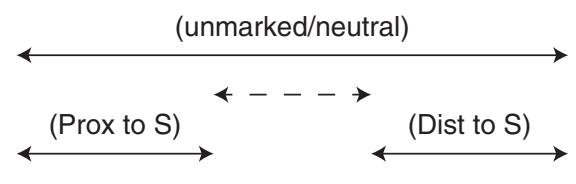

(b) e.g. Tiriyó, Tidore

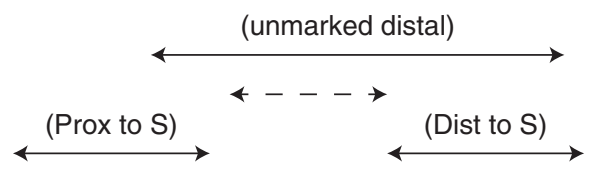

(c) Unattested, but the two-term Lao system suggests this could perhaps occur

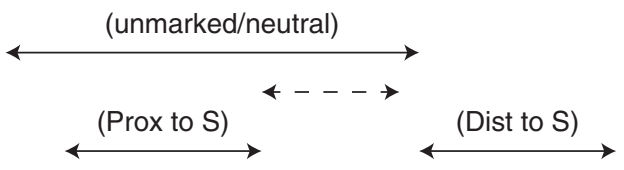

Figure 1.7 Three ways in which 'medial' terms may actually be unmarked terms (dotted extensions show areas where a neutral functions like a medial because it is not pre-empted by other terms)

demonstratives (setting aside for the moment the absolute dimensions in Tidore as well as the intrinsic dimensions in Jahai - the diagram shows what Burenhult calls the 'accessibility' demonstratives for Jahai). Figure 1.8 presents these spatial oppositions abstracted out of the many additional dimensions that structure these demonstrative sets.

Clearly there are many different kinds of systems here, in fact only the pairs Chukchi and Warao, Goemai and Brazilian Portuguese, and Tidore and Lavukaleve (and possibly Saliba and Trumai) appear to make very similar oppositions - with the upshot that there are 11 or 12 distinct systems in the sample of 15 languages. Nevertheless, Figure 1.8 makes clear some striking regularities across the systems. Nearly all systems have a speaker-based, or speaker-and-addressee-based, proximal - the exception here is Lao. Neutral or unmarked terms are common, contrary to Anderson and Keenan (1985) and Diessel (1999: 38). Hence there are grounds for suspicion that most if not all terms that might be described as 'medial' in descriptive grammars are in fact neutral or unmarked distal, and pick up their medial usage through privative opposition with proximal or far-distal terms (see Meira and Terrill, 2005). 

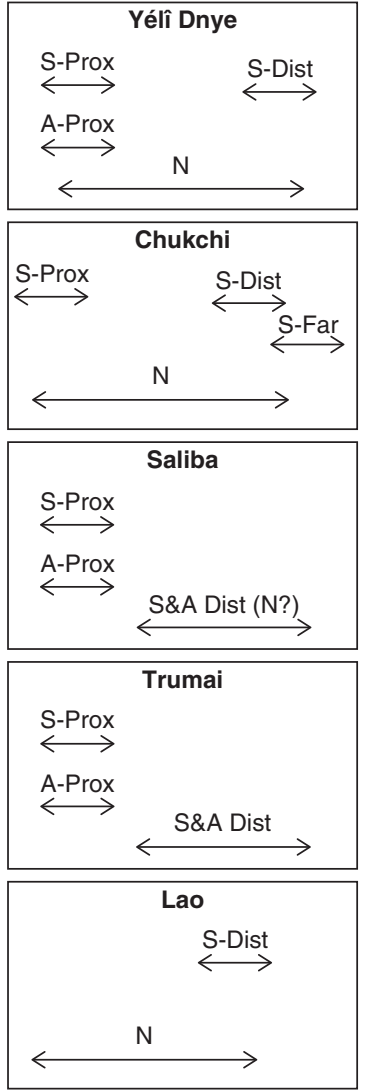
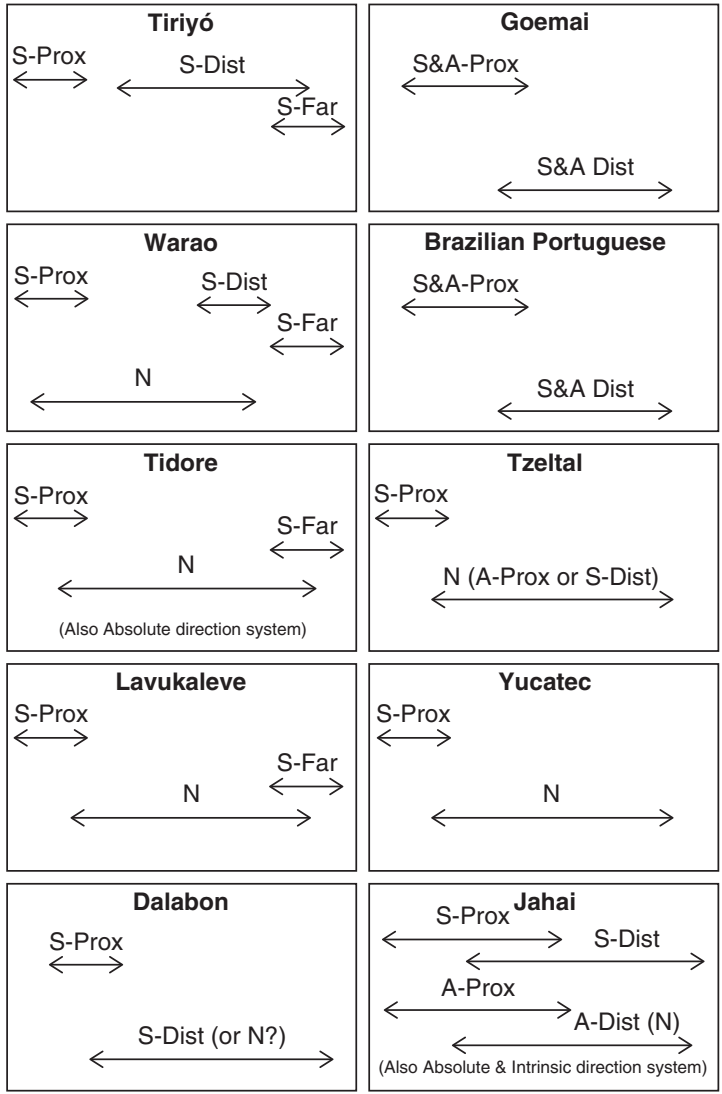

Figure 1.8 Sketch of the core proximity oppositions in nominal demonstratives in the 15 languages $(\mathrm{N}=$ neutral or unmarked, Far is far distal, $\mathrm{S} \& \mathrm{~A}$ is a joint speaker-addressee anchor)

\subsubsection{Other Kinds of Spatial Information in Deictic Systems: Direction}

So far we have been considering spatial distinctions which effectively, by coding or implicature, specify search-domains that are at distances notionally or in idealized form radial from speaker or addressee or both (note though the kind of 'deformation' of such radial areas in, for example, the cardioid pattern in Figure 1.3). On the grounds that these terms do not normally specify angular or directional information, Levinson $(1996 ; 2003)$ proposed that demonstrative systems should not be considered spatial frames of reference, that is, a system of cognitive coordinates capable of specifying a direction. He was particularly keen to point out that what had been called 'the deictic frame of reference' was 
actually a more complex system involving projected origos and angles, and not necessarily involving the deictic centre, which he called 'the relative system' (involving in English expressions like left, right, front, back). A good sample of cross-linguistic analyses of frames of reference in languages can be found in Levinson and Wilkins (2006). Frames of reference have been of particular interest to the psychology of space, and Levinson (2003) distinguished three kinds of basis for spatial reckoning which may be reflected in languages:

(i) the intrinsic frame of reference which uses the designated facets of ground objects (as in 'in front of St Peters in Rome', the 'intrinsic frame of reference'),

(ii) the relative frame of reference which maps ego's or alter's own coordinates (left, right, front, back) on the environment (as in 'he left his glasses to the left of the phone'),

(iii) the absolute frame of reference which maps geographic or abstract external coordinates onto local arrays, as in 'I left the mattock north of the tree'.

Since then a number of objections have been made to the demotion of a deictic frame of reference (Diessel, 1999, 2014), on the basis, for example, that (a) demonstratives are deictic, mostly speaker anchored, mostly with spatial distance coding, and clearly a fundamental type of expression across languages, and (b) they are normally accompanied by a gesture providing the angular information. With regards to the second point, the chapters in this book make clear that pointing is by no means essential or general with demonstratives, and indeed the gestural uses are often distinctively different from the non-gestural ones - for example, proximity is typically enlarged by pointing.

Perhaps a stronger point is that the demonstrative terms themselves sometimes encode angular information, usually of a geocentric or 'absolute' sort. Burenhult (2008) proposes a typology of angular information encoded in demonstratives which seems to be of two kinds. The first, noted early on by grammarians, is that some languages encode absolute (geocentric) direction, or array-external directions, the most common being information about whether the referent is above or below the deictic centre. Although grammars are rarely explicit about this, a word or affix meaning 'that up there' may indicate that the referent is literally higher than the deictic centre, or that it lies on a notional gradient (upriver/downriver, uphill/downhill) which actually delivers an angle on the horizontal. Alternatively, demonstratives may actually directly make reference to absolute coordinates, although these are usually glossed in terms of geographical gradients. These phenomena were already noted in Anderson and Keenan (1985) and before. But Burenhult (2008) adds that demonstrative systems may also make use of an intrinsic or array-internal frame of reference.

These 'absolute' and 'intrinsic' directionalities are attested in this volume by two languages which offer perhaps the most elaborate systems here reviewed: 
Tidore and Jahai. Tidore has a core system with a proximal, a distal and far distal, pretty much equivalent to Lavukaleve (see Figure 1.8 above). But superimposed on this, Tidore has two geographically anchored axes - an 'up/down' axis, and a 'seaward/landward' axis. The interpretation of the 'up/down' axis is particularly complex, since it can be driven by verticality, lay of the land, direction of the royal palace, sea currents, etc. These absolute or geocentric axes constrain the distal term, so by pragmatic presumption producing a four-way differentiation between speaker-proximal, distal, far-distal and geographic space where geocentric coordinates kick in. The Jahai system illustrates the possibility of having demonstratives encoding not only externally anchored terms in an absolute frame of reference but array-internal organization in an intrinsic frame of reference. But the core of the system has speaker-based versus addressee-based opposition, crossed with an accessibility parameter, yielding four central terms. Superimposed on this is an absolute or geographical external 'up/down' opposition, which can have either a vertical interpretation or a horizontal interpretation in terms of upriver/downriver direction. Then, in addition, there is an intrinsic or array-internal mode of calculating direction, which Burenhult (2008; this volume) calls 'exterior', which distinguishes referents on the side of the participant away from the shared interaction space, as sketched below in Figure 1.9 (but see Burenhult, this volume). Hanks (2011) points to West Greenlandic as possibly making similar distinctions. Burenhult's analysis may well apply to other systems less well described, but this awaits further research; for example, it appears to apply to the usage conditions for the proximal in Tidore, because the zone of proximity there extends further out on the side away from the addressee. Burenhult (2008: 113-114) suggests that some of the motion demonstratives that have been reported elsewhere which generalize to or from alignment demonstratives (as in Nunggubuyu) may also involve an intrinsic frame of reference. Burenhult also notes as a generalization that demonstratives in the relative frame of reference, e.g. meaning 'that to the left' do not seem to exist
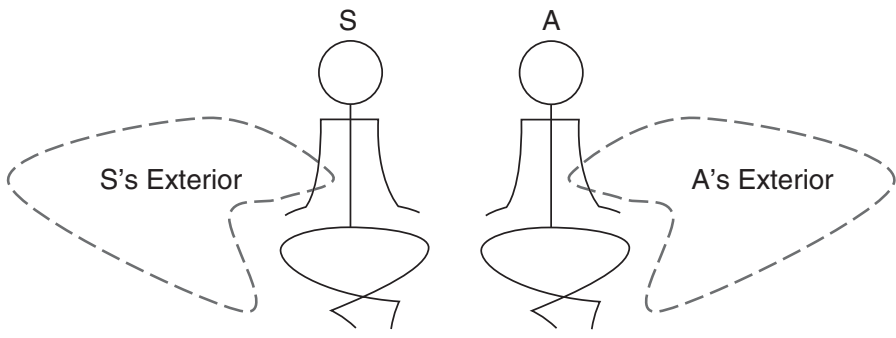

Figure 1.9 Sketch of Jahai notion of 'exterior' space 
(although colloquial Tamil in usage allows a left/right bias to the interpretation of proximal/distal forms: Levinson, 2003: 108).

\subsubsection{Non-spatial Distinctions in Demonstratives}

The usage of all of the systems described involves many non-spatial criteria, including whether the referent has been mentioned before, is in the current addressee's focus of attention, is visible, is manipulable and so forth - many of these factors operate to constrain the relevant notions of proximity without being in any way encoded in the semantics of the terms (see, e.g., Chapter 3 on Lao). Clearly systems that mark gender, number and other properties of the referent (as in Trumai, Tiriyó, Goemai and Lavukaleve) involve coding of nonspatial attributes, but these are non-deictic in character. Some languages (like Tariana (Aikenvald, 1994) or Kilivila (Senft, 1996; 2004)) combine classifiers with demonstratives, and what is represented in this book is an unusual obligatory combination in Goemai of demonstrative and a positional classifier element, which specifies whether the referent is sitting, standing, hanging or lying. The positional information is spatial, but not deictic, as it does not depend on speaker or addressee's location.

Nevertheless, there are important deictic non-spatial properties that get coded directly in the semantics of demonstratives and don't just constrain normal usage, and these parameters are briefly reviewed in the paragraphs that follow.

\section{Attention}

As mentioned at the outset, part of the root function of demonstratives seems to be to manipulate attention (Diessel, 2006). Earlier studies of Turkish and Japanese have suggested that attentional parameters may be built into the semantics of demonstratives: a re-analysis of Turkish demonstratives for example shows a distinction between şu (not yet in joint attention) and two other forms ( $b u$ and $o$ ) that presume joint attention and distinguish proximity (Küntay and Özyürek, 2002). Elaborating some suggestions by Diessel (2006), Burenhult (this volume) considers demonstratives to be 'attention managers' and makes a useful distinction between attention-drawers (with a subtype attention-correctors) and attention-confirmers, which in Jahai require different forms (Burenhult, 2003). The forms in question belong to one of three dimensions that structure the nine-way demonstrative oppositions in Jahai, a dimension Burenhult calls 'accessibility', a dimension we return to below. In Goemai, the main function of demonstratives is to draw attention to, and identify, the referent; this contrasts with Trumai, where demonstratives can be used only if attention is already on the referent or perhaps more generally on the interactive space. Chukchi has particles or clitics that prefix to the demonstratives forming terms which serve specifically to draw the addressee's attention 
to the referent, and consequently normally occur with a point. Tzeltal has a proximal component (in-) that has a presentational quality, presumes visibility and draws attention to the referent. Similarly, Yucatec uses the presentational prefix on the demonstratives in order to draw the addressee's attention to the referent. Saliba tends to use demonstrative adverbs to draw attention to referents. In contrast, the Yélî Dnye speaker- and addressee-proximals both presuppose mutual attention is already on the referent - hence the unmarked neutral must be used to draw attention to the referent. Tiriyó offers two forms of the proximal, one for drawing attention to new referents, and one that presupposes that attention is already drawn (it is thus typically an anaphoric). In sum, attentional distinctions are often built into demonstrative systems, and more generally, even in familiar languages, seem to play a role in their usage (see, e.g., Piwek et al., 2008; Peeters et al., 2014 on Dutch).

\section{Visibility}

Many of the chapters refer to the relevance of the visibility or otherwise of the referent. However, in the cases reviewed, visibility seems to be more a criterion constraining use than a part of the demonstrative semantics. In Chukchi an invisible referent tends to force a periphrastic construction (glossing, e.g., 'which is there') instead of a demonstrative, and a similar constraint is found in Goemai and Warao. In Tzeltal, there are constraints on the proximal forms, which seem to require visibility of referent. Saliba has a pragmatic condition on the visibility of referents - if they are not visible, they are presumed to have been mentioned or previously established, in which case the anaphoric element preempts the demonstratives; alternatively, a periphrastic form with the demonstrative adverbs is employed. In Yucatec, a presentative form of the deictic is used for calling attention to a referent in the immediate visual field, whereas when the referent is not in that field, an adverbial form (glossing 'that there') is used.

Other chapters show that what on earlier accounts was thought to be a visibility distinction in fact turns out to have a more evidential character, to do with indirect or non-visual evidence (see the chapters on Yélî Dnye, Tiriyó and Jahai), as discussed immediately below.

\section{Mode of Apprehension, Evidentiality: An Epistemic Dimension}

Jahai has a demonstrative reserved for referents recognized only through their emissions, by sound or smell or inward pain. At first sight an 'invisible' term, it in fact cannot be used for referents directly touched as well as those not seen. In a similar way, Yélî Dnye has a term $w u$ that on earlier accounts was reserved for invisible referents, but on close analysis refers to referents indirectly inferable: it cannot be used for invisible things whose location is clearly known. A typical use is 'What's that $(w u)$ ?' when hearing a sound of unknown origin. Exactly the same kind of usage is reported from Tiriyó for the demonstrative previously thought to be reserved for the invisible, but which in fact 
refers to an audible but invisible referent - a non-audible invisible referent cannot be so referred to.

In the dialect of Yucatec studied by Hanks (1990), there is a terminal particle used for referents audible but not visible; this is absent from the Yucatec studied by Bohnemeyer (this volume), but usage of the other deictics is also governed by this kind of evidential dimension - if one cannot see the referent but knows it is there, the distal demonstrative is paired with the distal adverb (te' $l-o$ ').

\section{Accessibility}

A number of the chapters describe a criterion for proximity that can best be characterized as reachability, corresponding closely to the peripersonal space of neurology. For example, in Yélî Dnye the speaker- and addressee-proximals both have strong conditions on their use: if the referent is in the hand or within easy grasp, these proximals must be used in normal circumstances, strongly pre-empting the unmarked neutral term. In Saliba a referent that when sitting cross-legged is reachable is referred to with the proximal, but when one stretches the legs out forwards and it becomes not easily reachable, the proximal is no longer preferred. In Yucatec, the speaker-anchored proximal is used whenever the referent is in reach, and mostly not when the referent is out of reach. Reaching is also reported as the relevant criterion for the Lavukaleve and Tidore proximals. We have already seen how this accessibility criterion may create a cardioid pattern around speaker or addressee, where things behind one cannot easily be reached without turning around, although this is curiously variable across languages (e.g., in Yucatec the proximal can still be used for referents behind one). In some of the languages where this pattern arises, it seems to be an outcome of another constraint, namely that the referent should be visible, as in Warao. But in others it seems to be a genuine constraint based on reaching without effort. Thus Brazilian Portuguese makes an accessibility distinction in the distal compound (pronominal-adverbial) forms, between places that are easy versus hard to access. Notice that these findings are in line with recent experimental work on European demonstratives (Peeters et al., 2014); Coventry et al. (2008) found that increasing subjects' reach with a stick increased the scope of the proximal.

Jahai also has terms that could roughly be glossed as speaker- versus addressee-anchored proximal/distal oppositions, but Burenhult argues that the fine detail of usage argues for an analysis in terms of accessibility: e.g. if a speaker-accessible form can be used for a referent $\mathrm{X}$, but an obstacle is placed between $\mathrm{X}$ and the speaker, the accessible form is no longer felicitous. Thus reachability and approachability play a crucial role, but the notion of accessibility is also conceptual and refers to whether a referent is or is not in the common ground or attention of speaker and addressee. Dalabon appears to have specialized demonstratives that make this distinction, which are alternatives to a proximal/distal set that is also in the inventory. 


\section{Contrastive Use}

The central task used to generate the findings presented in this volume specifically avoided contrastive uses of the demonstratives (i.e. contrastive as in This one not that one). Nevertheless remarks on contrastive uses will be found throughout the volume. In addition, a number of the authors ran the extra task, specifically designed to explore contrastive uses, as in 'Eliciting contrastive use of demonstratives for objects within close personal space' by David Wilkins (1999b). One of the findings from this volume is that although there do not often seem to be distinct contrastive forms (but see, e.g., Schapper and San Roque, 2011 on Bunaq), contrastive uses are generally different from noncontrastive uses and rarely follow the English pattern where in contrastive contexts first reference uses the proximal and second reference uses the distal demonstrative as in First take this pill, then that one (Fillmore, 1997). One pattern is neutralization of proximity. Thus Chukchi speakers tended to revert to the same proximal form if A is contrasted with B in table-top space, as did Lavukaleve and Yucatec speakers; Dalabon speakers also prefer this but may deploy their special 'common ground' form for a distal referent in table-top space if pointing is disallowed. Another pattern is that order of mention is irrelevant, and proximity determines the forms used, as in Yélî Dnye; the same holds in Saliba unless the referents are equidistant from the speaker, in which case only in the contrastive use is the proximal contrasted to the distal for equidistant referents. The study of contrastive use can throw considerable light on the meanings of terms: true neutrals resist contrastive use, while distalneutrals allow such usage (Meira and Terrill, 2005).

\section{Gesture and Pointing}

The demonstrative task aimed to gather information about both gestural and non-gestural uses. One emerging result of this volume is that a pointing gesture extends the proximal zone, in some cases indefinitely. This is true in, e.g., Tzeltal, Saliba, Yucatec, Tiriyó, Lavukaleve and Dalabon. It seems that the gesture often has a presentational quality and this is what extends the proximal zone: thus Tzeltal gesture forces use of the proximal or presentative form, which then has extensive range right up to the horizon. Similarly, in Lavukaleve the presentative form of the demonstrative requires a point, and pointing occurs specifically with the presentative form. In Tiriyó, too, the gesture forces use of a proximal form for close referents and shrinks the space so that middle-distance referents can get the proximal.

In a number of languages, the proximal forms require a gesture. Yélî Dnye proximals must be accompanied by a pointing gesture, or at least gaze, unless the referent is actually being manipulated. In Yucatec, the proximal forms must be accompanied by a gesture. In Saliba, pointing is associated with the speakerbased proximal rather than the addressee-based one, and pointing clearly 
extends the range of this proximal. In other languages like Warao, apparently all the exophoric demonstratives must be accompanied by a gesture, and if one's hands are full, a dedicated anaphoric (or established referent) form must be used instead. In Tiriyó, touching or close pointing requires the proximal demonstrative.

The discussion so far has been loose about 'gesture', although as far as we know pointing with the index finger is universally available (although supplemented by other bodily indications in many other cultures). Some have suggested that the function of the demonstrative is to draw attention to the pointing, which then directs attention to the referent (Bangerter, 2004). Alternatively one might claim that it is the gaze that actually does the work, the gesture drawing attention in turn to the gaze (see Enfield, 2001 on lip-pointing). Again, here we find cultural diversity. Some of the chapters provide specific information on the form of pointing associated with the demonstratives. Chukchi uses the index finger point, Tzeltal the index point for locations and the flat palm down for directions, Dalabon, Lao, Tiriyó and Yélî Dnye also offering lip- or head- and eye-pointing. In some languages, especially those that use an absolute frame of reference elsewhere in their spatial system, pointing may not be accompanied by gaze in the same direction (Levinson, 2003). Although lip- or head-pointing may be occasioned by occupation of the hands, when the hands are free it may have a special role as a demoted gesture (suggesting, for example, that the referent is obvious, or we shouldn't point at the referent out of respect; see Enfield, 2001). In some cultures there are systematic taboos, for example on pointing with the left hand (Kita and Essegbey, 2001). More systematic information on this issue would be useful in future work on demonstratives (see Wilkins et al., 2007 for suggestions about data collection, and Kita, 2003).

An interesting possibility is that gesture becomes less prominent in systems with more information encoded in the semantics of demonstratives, for example with directional, animacy, gender, number and classifier information. This would be in line with recent experimental findings that show longer, slower pointings when these are carrying the main directional information (Peeters, Chu, et al., 2015; see also Bangerter, 2004), but there are no more than hints in this direction from the chapters in this book.

\section{Dedicated Anaphorics in Demonstrative Paradigms}

This volume is focused on exophoric reference where demonstratives indicate referents in the speech situation, because this usage seems to be primary (e.g. learned first in childhood) and is the usage that has intrigued philosophers, psychologists and linguists. But many demonstrative systems use the same forms in exophoric (contextual) and endophoric reference (or anaphora sensu lato). In English, for example, 'that X' (as in 'That woman you mentioned') can refer backwards (anaphorically sensu stricto) to a previously mentioned 
referent, while 'this X' is likely to be forward looking or cataphoric (as in "This strange guy came up to me and asked for a dime"). English has third person pronouns, but many languages (e.g. some Australian ones, but not Dalabon in this volume) instead use demonstratives in this function. Where there is use both environmentally and textually, the two usages may not influence one another. But where a language provides a whole different set of forms for anaphoric reference, they may obviate the use of demonstratives in an endophoric function, as in Goemai, Lavukaleve or Yélî Dnye. Consider, for example, Yélî Dnye, as described in this volume: you can point at a referent and refer to it with, say, a speaker-centric demonstrative ala 'this', but the very next reference to that object even when accompanied by a point must use the dedicated anaphoric form (yi), even though this is still a deictic as well as an anaphoric usage. In this way the possession of a dedicated anaphoric system may make a very real difference to the use of demonstratives, and this obviation needs to be mentioned in any good description. In Warao, for example, the exophoric forms have an obligatory accompanying pointing gesture, while the anaphoric form picks up already established referents or those where no gesture can be made (because, for example, the hands are otherwise occupied). In Tiriyó, two forms of the proximal seem in fact to be specialized, one for drawing attention to a referent, and another that presumes prior attention through earlier reference.

\section{Conclusions: Some Generalizations about Demonstrative Systems}

One of the clear messages of this volume is that current typologies of demonstratives are inadequate, and we are far from being able to formulate tight 'universals' of demonstratives. What we are now in a position to do, however, is to lay out the semantic parameters of the design space for demonstratives that is, the dimensions on which they vary. These dimensions are summarized in Table 1.5, where these parameters can be partially cross-combined, so that, for example, one can have an addressee-anchored proximal, but not apparently an addressee distal. Where constraints are known to be likely, they are listed below in Table 1.6, as possible generalizations. The reason that a proper typology, as a tree of possibilities, currently escapes us is that the constraints on the co-occurrence of these features are largely unknown. Obviously, where there are only two terms, the possibilities are limited, but for three or more terms the parameters in Table 1.5 offer many possibilities.

Perhaps it makes sense to ask the following question: if cultural evolution is going to make a two-opposition system, or a three- or four- or more opposition system, which semantic features are likely to be selected at each increment of oppositions or terms? Given the remarks above we should dispense with the 
Table 1.5 Semantic parameters involved in the 'design space' of demonstrative oppositions

\begin{tabular}{|c|c|c|c|}
\hline \multirow[t]{2}{*}{ Parameters } & \multicolumn{3}{|c|}{ Values } \\
\hline & speaker & addressee & speaker \& addressee \\
\hline Proximity & reach & interaction area & beyond interaction area \\
\hline Distality & unmarked distal & far distal & \\
\hline Unmarked & neutral & unmarked distal & \\
\hline Access & $\begin{array}{l}\text { accessible, no } \\
\text { obstacle }\end{array}$ & Inaccessible, obstacle & \\
\hline Attention & drawing & presupposing & correcting \\
\hline Absolute direction & vertical & horizontal & \\
\hline Intrinsic direction & single participant & joint participant & \\
\hline Evidential & non-visible & audible, smellable & indirectly ascertained \\
\hline Gesture & with point & without point & other kinesic index \\
\hline Dedicated anaphorics & nominal & adverbial & \\
\hline Properties of referent & number, gender & animacy & classifier category, etc. \\
\hline Emotional affect & $\begin{array}{l}\text { positive affect to } \\
\text { referent }\end{array}$ & $\begin{array}{l}\text { negative affect to } \\
\text { referent }\end{array}$ & $\begin{array}{l}\text { speaker-addressee } \\
\text { relationship }\end{array}$ \\
\hline
\end{tabular}

counting of terms, the formal exponents of difference, and concentrate rather on the basic semantic oppositions that are made, selecting from the parameters in Table 1.5. Here the distribution of features that have been described in this volume may be illuminating when laid out as a tree of incremental possibilities from top to bottom, as in Figure 1.10. It is tempting to interpret the tree in diachronic light, as the order in which oppositions might be added, but as Diessel (1999) points out, the historical sources of demonstratives are usually opaque. One should note that there appears to be considerable freedom in whether, having made one distinction using feature $\mathrm{X}$ to yield terms $\mathrm{X} 1$ and $\mathrm{X} 2$, feature $\mathrm{Z}$ is used to make a subdivision of say $\mathrm{X} 1$, or whether $\mathrm{Z}$ may outrank $X$, and $X$ be used to yield subtypes of $Z$. For example, suppose we take the 'attention-drawing versus attention-confirming' parameter: in Turkish, this parameter would be the first split in a decision tree, with a secondary proximity distinction between the referents within joint attention (Küntay and Özyürek, 2002); but in Tiriyó one must first decide if the item is proximal, and then whether attention is already on the item or not.

We have arranged the papers in this book in line with the complexity order in Figure 1.10. Thus the book starts with chapters on Lao and Dalabon, both systems with speaker-based proximity systems, but in the case of Lao on a negative proximity base - a 'not here' term. We then proceed to systems anchored on both speaker and addressee, Brazilian Portuguese and Goemai - 
Two-opposition systems

Three-opposition systems

Four-opposition systems

Multi-opposition systems

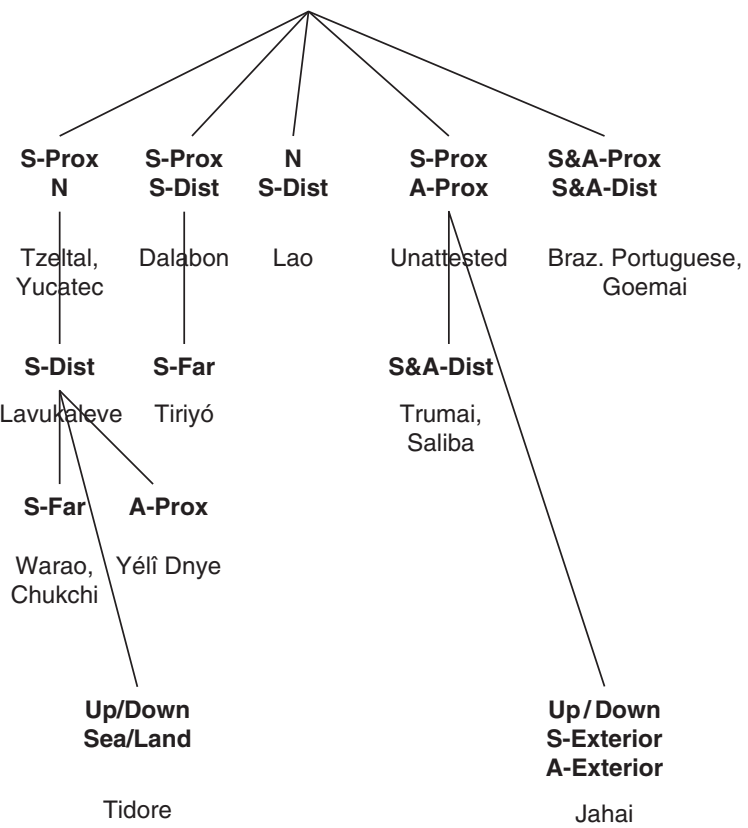

Figure 1.10 The nominal systems in this book laid out as a tree of increasing semantic complexity $(\mathrm{S}$-Prox $=$ speaker-based proximal term, $\mathrm{S}$-Dist $=$ speaker-based distal term, $\mathrm{S}$-Far $=$ speaker far-distal term, $\mathrm{N}=$ neutral term unmarked for proximity, A-Prox = addressee-based proximal, S\&A-Prox $/$ Dist $=$ speaker and addressee based proximal/distal)

Goemai introducing the complexities of a referent classifier system. Chapters on Tzeltal and Yucatec complete the coverage of systems based primarily on a binary opposition - since their formal exponents are many and complex, they introduce additional semantic parameters like presentational elements. We then proceed to systems that introduce a third semantic element, starting with speaker-anchored systems in Lavukaleve and Tiriyó which differ in the semantic nature of their third term, and subsequently to chapters on systems where the third element is anchored on both speaker and addressee. Next come systems that introduce yet a further semantic element over and above a speaker-based three-element system - in Warao and Chukchi this involves the introduction of a speaker-based far-distal, while in Yélî Dnye it involves the introduction of an addressee-based term. Finally we come to systems that make multiple oppositions, and here we see yet again that such systems can be built on different bases: in Tidore, absolute directional terms are overlaid on a speaker-anchored core system, while in Jahai absolute and intrinsic directional terms are overlaid 
Table 1.6 Generalizations about demonstrative systems: Hypotheses based on this book

1. There is no addressee-anchored demonstrative without a corresponding speaker-anchored one.

2. It is rare, but possible (as shown by Lao), to have no speaker-based proximal.

3. There are no addressee-anchored distal demonstratives.

4. Speaker- and addressee-origos are not the only kind; speaker and addressee anchoring can be the only or main form of origo.

5. A demonstrative system should for functional reasons have wide spatial coverage of the environment of the speech event (although some spatial discontinuities may result from attentional/visibility/reachability criteria, as in Fig. 1.3). It follows that a two-term system with only a speaker-proximal and addressee-proximal two-term system is unlikely to be found, since coverage would be too partial.

6. Genuine medials (mid-distance) demonstratives may be hard to find, since they mostly seem to amount to unmarked neutrals or unmarked distals in privative opposition to proximals and fardistals.

7. Four or more distinctions will never be distance-based alone, but always involve additional parameters like switches of anchorage, evidential distinctions or frame of reference distinctions.

8. All demonstrative systems involve some notion of proximity, even if (as in the case of Lao) it is negative.

9. Spatial zones invoked by demonstratives can be expected to be continuous rather than discontinuous spaces.

10. Proximity notions are only metric and relatively inflexible in some proximal demonstratives, where reaching space of speaker, addressee or both may be involved.

11. Proximal notions often involve reaching criteria and thus may often not extend behind the origo or anchorage point (speaker or addressee).

12. Demonstrative systems may involve both the absolute and the intrinsic frames of reference, but never the relative frame.

13. Terms described as reserved for 'invisible' referents in grammars are more likely to have an evidential basis, being reserved for audible referents, or referents indirectly ascertained.

14. If a proximal allows concurrent pointing, pointing always extends the range of a speakeranchored proximal term.

15. Possession of a dedicated anaphoric pronoun or adverb in the paradigm will preclude use of the exophoric demonstratives in anaphoric function.

16. If there are more adverbial distinctions than nominal ones, adverbs and nominal demonstratives are more likely to occur as compound forms.

17. Contrastive uses of demonstratives tend to neutralize proximity distinctions.

18. Across languages, as the semantics of demonstratives becomes richer (with coding of direction and referent properties, for example), the importance and frequency of gesture declines.

on a basic opposition between speaker-based and addressee-based terms. The book illustrates very clearly how languages are largely free to pick and choose from the parameters in Table 1.5.

No reader of this volume can fail to be impressed by the diversity of the 15 systems reviewed in this book. They vary fundamentally in formal type, in the 
semantic distinctions they make, in the pragmatic variables they are sensitive to and the functions they perform. Even concentrating just on the distance or proximity distinctions, we have seen there are nearly as many types (12) as there are languages reviewed in this book (15). Nevertheless, in the spirit of universals research, one may hazard the generalizations in Table 1.6.

To conclude this introduction, demonstrative systems remain, as mentioned at the outset, a key 'model system' for the study of language in relation to its use. At first sight they seem quite simple, little signals of referential intention, but because they articulate the complexities of mutual awareness, of referent identification in the full three-dimensional sensorium of context and face-toface interaction, they can rapidly be seen to offer insights into the enormous complexity of the triadic attention (between speaker, addressee and referent) that nine-month-old infants are already beginning to glimpse (Tomasello et al., 2007). This makes demonstratives not only an interesting model system for cross-linguistic comparison, as in this book, but also a perfect laboratory for the study of language acquisition and the cognitive and neural underpinnings that make it possible (see, e.g., Peeters, Hagoort and Özyürek, 2015; Redcay and Saxe, 2013; Peeters et al., under review). One can be confident that future research will exploit the rich communicational infrastructure that crosslinguistic variation in demonstratives reveals.

\section{References}

Abney, S. (1987). The English noun phrase in its sentential aspect. PhD dissertation, MIT.

Aikhenvald, A. (1994). Classifiers in Tariana. Anthropological Linguistics, 36(4), 407-465.

Anderson, S. \& Keenan, E. (1985). Deixis. In T. Shopen, ed., Language typology and syntactic description. Vol. III. Cambridge: Cambridge University Press, pp. 259-308.

Bangerter, A. (2004). Using pointing and describing to achieve joint focus of attention in dialogue. Psychological Science, 15(6), 415-419.

Bangerter, A. \& Clark, H. H. (2003) Navigating joint projects with dialogue. Cognitive Science, 27, 195-225.

Bhat, D. N. S. (2004). Pronouns. Oxford: Oxford University Press.

(2013). Third person pronouns and demonstratives. In M. S. Dryer \& M. Haspelmath, eds., The world atlas of language structures online. Leipzig: Max Planck Institute for Evolutionary Anthropology. (Available online at http://wals.info/chapter/43, July 20 July 2016.)

Bohnemeyer, J. (2012). Yucatec demonstratives in interaction: Spontaneous vs. elicited data. In A. C. Schalley, ed., Practical theories and empirical practice. Amsterdam/ New York: John Benjamins, pp. 99-128. 
Bonfiglioli, C., Finocchiaro, C., Gesierich, B., Rositani, F. \& Vescovi, M. (2009). A kinematic approach to the conceptual representations of this and that. Cognition, 111(2), 270-274.

Braun, D. (2015). Indexicals. In E. N. Zalta, ed., The Stanford encyclopedia of philosophy. Spring edn. (Available online at http://plato.stanford.edu/archives/spr2015/ entries/indexicals/.)

Bühler, K. (1982 [1934]). The deictic field of language and deictic words. In R. Jarvella \& W. Klein, eds., Speech, place and action. Amsterdam: John Wiley, pp. 9-30. (Translated from Bühler, Karl. 1934. Sprachtheorie: Die Darstellungsfunktion der Sprache. Jena, Germany: Fischer).

Burenhult, N. (2003). Attention, accessibility, and the addressee: The case of the Jahai demonstrative ton. Pragmatics, 13, 363-379.

(2008). Spatial coordinate systems in demonstrative meaning. Linguistic Typology, 12, 99-142.

Clark, E. V. (1978). From gesture to word: On the natural history of deixis in language acquisition. In J. Bruner \& A. Garton, eds., Human growth and development. Oxford: Clarendon Press, pp. 85-120.

Clark, H. H. (1996). Using language. Cambridge/New York: Cambridge University Press.

Clark, H. H., Schreuder, R. \& Buttrick, S. (1983). Common ground and the understanding of demonstrative reference. Journal of Verbal Learning and Verbal Behaviour, 22, 245-258.

Coventry, K. R., Valdés, B., Castillo, A. \& Guijarro-Fuentes, P. (2008). Language within your reach: near-far perceptual space and spatial demonstratives. Cognition, 108 (3), 889-895.

Coventry, K. R., Griffiths, D. \& Hamilton, C. J. (2014). Spatial demonstratives and perceptual space: Describing and remembering object location. Cognitive psychology, 69, 46-70.

Da Milano, F. (2005). La deissi spaziale nelle lingue d'Europa. Milan: Angeli.

Diessel, H. (1999). Demonstratives: Form, function, and grammaticalization. Amsterdam: John Benjamins.

(2006). Demonstratives, joint attention, and the emergence of grammar. Cognitive Linguistics, 17(4), 463-489.

(2013a). Pronominal and adnominal demonstratives. In M. S. Dryer \& M. Haspelmath, eds., The world atlas of language structures online. Leipzig: Max Planck Institute for Evolutionary Anthropology. (Available online at http:// wals.info/chapter/42, accessed 15 January 2016.)

(2013b). Distance contrasts in demonstratives. In M. S. Dryer \& M. Haspelmath, eds., The world atlas of language structures online. Leipzig: Max Planck Institute for Evolutionary Anthropology. (Available online at http://wals.info/chapter/41, accessed 16 January 2016.)

(2014). Demonstratives, frames of reference, and semantic universals of space. Language and Linguistics Compass, 8(3), 116-132.

Dixon, R. M. W. (2003). Demonstratives: A cross-linguistic typology. Studies in Language, 27(1), 61-112.

Enfield, N. J. (2001). 'Lip-pointing': A discussion of form and function with reference to data from Laos. Gesture, 1(2), 185-211. doi:10.1075/gest.1.2.06enf. 
(2003). Demonstratives in space and interaction: Data from Lao speakers and implications for semantic analysis. Language, 79(1): 82-117.

Fillmore, C. J. (1982). Towards a descriptive framework for spatial deixis. In R. J. Jarvella \& W. Klein, eds., Speech, place and action: Studies in deixis and related topics. New York: Wiley, pp. 31-60.

(1997). Lectures on deixis. Stanford, CA: CSLI Publications.

Frei, H. (1944). Systèmes de deictiques. Acta Linguistica, 4, 111-129.

Gallotti, M. \& Frith, C. D. (2013). Social cognition in the We-mode. Trends in Cognitive Sciences, 17(4), 160-165.

Guérin, V. (2015). Demonstrative verbs: A typology of verbal manner deixis. Linguistic Typology, 19(2), 141-199.

Halliday, M. A. K. \& Hasan, R. (1976). Cohesion in English. London: Longman.

Hanks, W. F. (1990). Referential practice: Language and lived space among the Maya. Chicago: University of Chicago Press.

(1992). The indexical ground of deictic reference. In A. Duranti \& C. Goodwin, eds., Rethinking context: Language as an interactive phenomenon. Cambridge: Cambridge University Press, pp. 43-76.

(2005). Explorations in the deictic field. Current Anthropology, 46(2), 191-220.

(2009). Fieldwork on deixis. Journal of Pragmatics, 41, 10-24.

(2011). Deixis and indexicality. In W. Bublitz \& N. R. Norrick, eds., Handbook of pragmatics. Berlin: Mouton de Gruyter, pp. 315-346.

Himmelmann, N. (1996). Demonstratives in narrative discourse: A taxonomy of universal uses. In B. Fox, ed., Studies in anaphora. Amsterdam: John Benjamins, pp. $205-254$.

Jungbluth, K. (2003). Deictics in the conversational dyad: Findings in Spanish and some cross-linguistic outlines. In F. Lenz, ed., Deictic conceptualisation of space, time, and person. Amsterdam: John Benjamins, pp. 13-40.

Jungbluth, K. \& Da Milano, F., eds. (2015). Manual of Deixis in Romance Languages. Berlin: de Gruyter.

Kemmerer, D. (1999). 'Near' and 'far' in language and perception. Cognition, 73, $35-63$.

Kita, S. (2003). Pointing: Where language, culture, and cognition meet. Oxford: Psychology Press.

Kita, S. \& Essegbey, J. (2001). Pointing left in Ghana: How a taboo on the use of the left hand influences gestural practice. Gesture, 1, 73-95.

König, E. (2012). Le role des deictiques de manière dans le cadre d'une typologie de la deixis. Bulletin de la Société de Linguistique de Paris, 107(1), 11-42.

Kornfilt, J. (1997). Turkish. London: Routledge.

Küntay, A. C. \& Özyürek, A. (2002). Joint attention and the development of the use of demonstrative pronouns in Turkish. In B. Skarabela, S. Fish \& A. H. J. Do, eds., Proceedings of the 26th Annual Boston University Conference on Language Development. Somerville, MA: Cascadilla Press, pp. 336-347.

Küntay, A. C. \& Özyürek, A. (2006). Learning to use demonstratives in conversation: What do language specific strategies in Turkish reveal? Journal of Child Language, 33(2), 303-320. doi:10.1017/S0305000906007380. 
Levinson, S. C. (1996). Frames of reference and Molyneux's question: Cross-linguistic evidence. In P. Bloom, M. Peterson, L. Nadel \& M. Garrett, eds., Language and space. Cambridge, MA: MIT Press, pp. 109-169.

(2000). Presumptive meanings: The theory of generalised conversational implicatures. Cambridge, MA: MIT Press.

(2003). Space in language and cognition. Cambridge: Cambridge University Press. (2004). Deixis. In L. Horn, ed., The handbook of pragmatics. Oxford: Blackwell, pp. 97-121.

Levinson, S. C. \& Burenhult, N. (2009). Semplates: A new concept in lexical semantics? Language, 85, 153-174. doi:10.1353/lan.0.0090.

Levinson, S. C. \& Wilkins, D. (2006). Grammars of space. Cambridge: Cambridge University Press.

Liszkowski, U., Brown, P., Callaghan, T., Takada, A. \& De Vos, C. (2012). A prelinguistic gestural universal of human communication. Cognitive Science, 36, 698-713. doi:10.1111/j.1551-6709.2011.01228.x.

Lyons, J. (1977). Semantics. Vol. II. Cambridge: Cambridge University Press.

Meira, S. (2003). Addressee effects in demonstrative systems: The cases of Tiriyó and Brazilian Portuguese. In F. Lenz, ed., Deictic conceptualisation of space, time, and person. Amsterdam: John Benjamins, pp. 3-12.

Meira, S. \& Terrill, A. (2005). Contrasting contrastive demonstratives in Tiriyó and Lavukaleve. Linguistics, 43(6), 1131-1152.

Naruoka, K. (2006). The Interactional functions of the Japanese demonstratives in interaction. Pragmatics, 16(4), 475-512.

Özyürek, A. (1998). An analysis of the basic meaning of Turkish demonstratives in faceto-face conversational interaction. In S. Santi, I. Guaitella, C. Cave \& G. Konopczynski, eds., Oralité et gestualité: Communication multimodale, interaction. Paris: L'Harmattan, pp. 609-614.

Pagel, M., Atkinson, Q. D., Calude, A. S. \& Meade, A. (2013). Ultraconserved words point to deep language ancestry across Eurasia. PNAS, 110, 8471-8476.

Peeters, D. \& Özyürek, A. (2016). This and that revisited: A social and multimodal approach to spatial demonstratives. Frontiers in Psychology, 7, article 22 (February 2016).

Peeters, D., Chu, M., Holler, J., Hagoort, P. \& Özyürek, A. (2015). Electrophysiological and kinematic correlates of communicative intent in the planning and production of pointing gestures and speech. Journal of Cognitive Neuroscience, 27(12), 2352-2368. doi:10.1162/jocn_a_00865.

Peeters, D., Hagoort, P. \& Özyürek, A. (2015). Electrophysiological evidence for the role of shared space in online comprehension of spatial demonstratives. Cognition, 136, 64-84.

Peeters, D., Snijders, T. M., Hagoort, P. \& Özyürek, A. (under review). The neural integration of pointing gestures and speech in a visual context: An fMRI study. Ms.

Peeters, D., Zeynep, A. \& Özyürek, A. (2014). The interplay between joint attention, physical proximity, and pointing gesture in demonstrative choice. In Proceedings of the 36th annual meeting of the Cognitive Science Society. Austin, TX: Cognitive Science Society, pp. 1144-1149.

Perkins, R. D. (1992). Deixis, grammar and culture. Amsterdam/Philadelphia: John Benjamins. 
Piwek, P., Beun, R.-J. \& Cremers, A. (2008). 'Proximal' and 'distal' in language and cognition: Evidence from deictic demonstratives in Dutch. Journal of Pragmatics, 40, 694-718.

Redcay, E. \& Saxe, R. (2013). Do you see what I see? The neural bases of joint attention. In H. S. Terrace \& J. Metcalfe, eds., Agency \& joint attention. New York: Oxford University Press, pp. 216-237.

Rosés Labrada, J. E. (2015). Grammaticalization of lexical elements as deictics: Evidence from Sálibani. Talk to MPI Nijmegen Grammar Group, 27 August 2015. Schapper, A. \& San Roque, L. (2011). Demonstratives and non-embedded nominalisations in three Papuan languages of the Timor-Alor-Pantar family. Studies in Language, 35(2), 380-408.

Schelling, T. C. (1960). The strategy of conflict. Cambridge, MA: Harvard University Press.

Senft, G. (1996). Classificatory particles in Kilivila. New York: Oxford University Press.

ed. (1997). Referring to space: Studies in Austronesian and Papuan languages. Oxford: Clarendon Press.

ed. (2004). Deixis and demonstratives in Oceanic languages. Canberra: Pacific Linguistics.

Smith, N., ed. (1982). Mutual knowledge. London: Academic Press.

Stevens, J. \& Zhang, Y. (2013). Relative distance and gaze in the use of entity-referring spatial demonstratives: An event-related potential study. Journal of Neurolinguistics, 26(1), 31-45.

Tanz, C. (1980). Studies in the acquisition of deictic terms. Cambridge: Cambridge University Press.

Tomasello, M., Carpenter, M., Call, J., Behne, T. \& Moll, H. (2005). Understanding and sharing intentions: The origins of cultural cognition. Behavioral \& Brain Sciences, 28(5), 675-691.

Tomasello, M., Carpenter, M. \& Liszkowski, U. (2007). A new look at infant pointing. Child Development, 78, 705-722.

Umbach, C. \& Gust, H. (2014). Similarity demonstratives. Lingua 149, 74-93.

Van der Auwera, J. \& Sahoo, K. (2015). On comparative concepts and descriptive categories, such as they are. Acta Linguistica Hafniensa, 47(2), 136-173.

Weissenborn, J. \& Klein, W., eds. (1982). Here and there: Cross-linguistic studies on deixis and demonstration. Amsterdam: John Benjamins.

Wilkins, D. P. (1999a; this volume). The 1999 demonstrative questionnaire: 'This' and 'that' in comparative perspective. In D. P. Wilkins, ed., Manual for the 1999 field season. Nijmegen: Max Planck Institute for Psycholinguistics, pp. 1-24.

(1999b). Eliciting contrastive use of demonstratives for objects within close personal space (all objects well within arm's reach). In D. P. Wilkins, ed., Manual for the 1999 field season. Nijmegen: Max Planck Institute for Psycholinguistics, pp. 25-28. (Available online at http://fieldmanuals.mpi.nl/volumes/1999/elicitingcontrastive-demonstratives-personal-space/.)

Wilkins, D. P., Kita, S. \& Enfield, N. J. (2007). 'Ethnography of pointing': Field worker's guide. In Asifa Majid, ed., Field manual volume 10. Nijmegen: Max Planck Institute for Psycholinguistics, pp. 89-95. (Available online at http://field manuals.mpi.nl/volumes/2007/ethnography-of-pointing/.) 